\title{
What Modulates the Intensity of Synoptic-Scale Variability over the Western North Pacific during Boreal Summer and Fall?
}

\author{
RENGUANG Wu, ${ }^{\mathrm{a}, \mathrm{b}, \mathrm{c}}$ YUQI WANG, ${ }^{\mathrm{b}, \mathrm{d}}$ AND XI CAO ${ }^{\mathrm{b}}$ \\ ${ }^{a}$ School of Earth Sciences, Zhejiang University, Hangzhou, China \\ ${ }^{\mathrm{b}}$ Center for Monsoon System Research, Institute of Atmospheric Physics, Chinese Academy of Sciences, Beijing, China \\ ${ }^{\mathrm{c}}$ Southern Marine Science and Engineering Guangdong Laboratory (Zhuhai), Zhuhai, China \\ ${ }^{\mathrm{d}}$ College of Earth and Planetary Sciences, University of Chinese Academy of Sciences, Beijing, China
}

(Manuscript received 23 June 2020, in final form 22 January 2021)

\begin{abstract}
The present study investigates the factors that affect the year-to-year change in the intensity of synopticscale variability (SSV) over the tropical western North Pacific (TWNP) during boreal summer and fall. It is found that the intensity of the TWNP SSV in summer is associated with the equatorial central-eastern Pacific sea surface temperature (SST) anomalies that modulate the background fields through a Rossby wave response both in the source region and along the propagation path of the synoptic-scale disturbances. In fall, the intensity of the TWNP SSV is related to an SST anomaly pattern with opposite anomalies in the equatorial central Pacific and TWNP that modulates the background fields from the equatorial central Pacific to TWNP. However, the equatorial central Pacific SST anomalies alone fail to change the intensity of the TWNP SSV as the induced background field changes are limited to the equatorial central Pacific. It is shown that tropical western Pacific SST anomalies may induce notable changes in the intensity of the TWNP SSV. The relation of the TWNP SSV to the equatorial eastern Pacific SST is weak due to opposite SST anomalies in different types of years. Both seasonal mean and intraseasonal flows provide sources of barotropic energy for the change in the intensity of the TWNP synoptic-scale disturbances in summer. Seasonal mean flow has a main contribution to the barotropic energy conversion for the change in the intensity of the TWNP synoptic-scale disturbances in fall.
\end{abstract}

KEYWORDS: Sea surface temperature; Climate variability; ENSO; Interannual variability; Intraseasonal variability; Tropical variability

\section{Introduction}

Synoptic-scale disturbances are prominent in the tropical western North Pacific (TWNP) region during boreal summer and fall (Lau and Lau 1990; Sobel and Bretherton 1999; Maloney and Dickinson 2003; Straub and Kiladis 2003), which is related to the presence of a strong zonal convergence zone between the southwesterly monsoonal flows and easterly trade winds (Cao et al. 2012; L. Wu et al. 2012). These synoptic-scale disturbances affect the genesis of tropical cyclones over the TWNP (Holland 1995; Ritchie and Holland 1997; Fu et al. 2007; Chen and Huang 2009; Chen and Chou 2014; Cao et al. 2018), contribute largely to precipitation and convection over the TWNP (Hurley and Boos 2015) that may in turn affect remote regions through atmospheric circulation, and cause extreme rain events in coastal regions of Asia when they move northwestward to hit the land (Wu et al. 2011; Chen et al. 2012; Fukutomi et al. 2016). Thus, it is of considerable significance to understand what drive the changes in the intensity of synopticscale disturbances over the TWNP.

The environmental factors of synoptic-scale disturbances include low-level cyclonic vorticity, low-level convergence, and easterly vertical shear of winds (Sobel and Bretherton 1999; L. Wu et al. 2012; Molinari and Vollaro 2013; Zhou et al. 2018). As the synoptic-scale disturbances tend to be generated over the equatorial western-central Pacific and propagate

Corresponding author: Renguang Wu, renguang@zju.edu.cn northwestward (Lau and Lau 1990; Sobel and Bretherton 1999; Li 2006; Chen and Huang 2009), it is expected that any factors that modulate the background fields in the source region and/or along the propagation path of synoptic-scale disturbances can affect the activity of synoptic-scale disturbances.

El Niño-Southern Oscillation (ENSO) is an important factor for year-to-year changes in the synoptic-scale variability (SSV) over the TWNP as illustrated by previous studies (Chen and Huang 2009; Hsu et al. 2009; L. Wu et al. 2014). This is because ENSO can induce large wind changes over the TWNP (Wang et al. 2000, 2003; Wu et al. 2003). For example, the synoptic-scale disturbances are enhanced over the TWNP during El Niño years (Hsu et al. 2009). El Niño-induced eastward extension of the western Pacific monsoon trough results in an enhancement of synoptic-scale disturbances over the southeastern quadrant of the TWNP (Li and Zhou 2012; L. Wu et al. 2012, 2015a,b).

The intraseasonal oscillations can modulate the synoptic-scale activity over the TWNP (Sobel and Maloney 2000; Maloney and Hartmann 2001; Maloney and Dickinson 2003; Hsu et al. 2011; Zhao et al. 2015a,b). The active phases of intraseasonal oscillations tend to be accompanied by stronger synoptic disturbances (Maloney and Hartmann 2001; Maloney and Dickinson 2003; Hsu et al. 2011; Cao et al. 2012; Tsou et al. 2014). The barotropic energy conversion from the intraseasonal flow field contributes to the growth of the synoptic-scale disturbances (Sobel and Maloney 2000; Maloney and Dickinson 2003).

The temporal evolution and spatial distribution of ENSOrelated SST anomalies show diversity among individual ENSO 
events (Capotondi et al. 2015; Kirtman 2019). Thus, one question is whether there are different types of relationships between the intensity of the TWNP SSV and equatorial Pacific SST anomalies. It is indicated that local SST anomalies may contribute to wind changes over the TWNP (Wang et al. 2000; $\mathrm{Wu}$ and Wang 2000). Thus, another question is whether local SST anomalies can induce year-to-year changes in the intensity of the TWNP SSV. As the ENSO-related SST anomaly pattern differs between boreal summer and fall, an issue is whether the relationship of the TWNP SSV to the equatorial Pacific SST anomalies differs between summer and fall. The synoptic-scale disturbances may experience year-to-year changes in their origins, propagation paths, impact regions, and intensity. In this study, we focus on the changes in the intensity of the SSV.

The present study examines and compares the factors that contribute to the year-to-year changes in the intensity of the SSV over the TWNP in boreal summer and fall. In the rest of the present study, we describe the datasets and methods in section 2 . In section 3 , we document the seasonal change in mean and standard deviation of the intensity of SSV and the overall SST anomaly distribution related to the intensity of the TWNP SSV. In sections 4 and 5, we analyze in detail the factors that affect the intensity of the TWNP SSV in boreal summer and fall, respectively. Section 6 provides a summary of main results along with discussions.

\section{Datasets and methods}

Daily mean $850-\mathrm{hPa}$ winds and monthly mean 850 - and 200-hPa winds and 500-hPa vertical $p$ velocity used in the present study are provided by the National Centers for Environmental Predication-Department of Energy (NCEP-DOE) Reanalysis 2 (Kanamitsu et al. 2002). These variables are on $2.5^{\circ} \times 2.5^{\circ}$ grids for the period starting from January 1979 . The above reanalysis data are downloaded from ftp://ftp.cdc.noaa.gov/.

Monthly mean SST data used in the present study are the National Oceanic and Atmospheric Administration (NOAA) optimum interpolation (OI) version 2 (Reynolds et al. 2002). This SST dataset is on a $1^{\circ} \times 1^{\circ}$ grid and covers the period of December 1981 to the present. The NOAA OI version 2 SST data are provided by the NOAA/OAR/ESRL Physical Sciences Department (PSD), Boulder, Colorado, and obtained through http://www.esrl.noaa.gov/psd/.

The synoptic-scale disturbances in the present study refer to the variations with periods shorter than 9 days. We use the original daily mean minus a 9-day running mean to obtain the synoptic-scale variations. The intensity of the SSV is measured by the kinetic energy of synoptic-scale wind variations at $850 \mathrm{hPa}$ as in previous studies (e.g., Zhou et al. 2018). The average value of the kinetic energy during June-August (JJA) and September-November (SON) is used to represent the intensity of the SSV in boreal summer and fall, respectively. Some previous studies used 3-8-day filtered wind fields to calculate the kinetic energy to represent the intensity of the SSV (Li et al. 2014; Zhao et al. 2016; Zhou et al. 2018). We perform a parallel analysis of 3-9-day synoptic-scale variations obtained using a 3-day running mean minus a 9-day running mean. Our comparison shows that the spatial distribution and temporal evolution of the intensity of the SSV based on the two methods are very similar although there is a difference in the magnitude.

The present study examines the relative contributions of different terms of the barotropic energy conversion to the synoptic-scale disturbances. The equation of the barotropic energy conversion is as follows:

$$
\frac{\partial K_{\text {baro }}^{\prime}}{\partial t}=-u^{\prime} v^{\prime} \frac{\partial \bar{u}}{\partial y}-u^{\prime 2} \frac{\partial \bar{u}}{\partial x}-v^{\prime 2} \frac{\partial \bar{v}}{\partial y}-u^{\prime} v^{\prime} \frac{\partial \bar{v}}{\partial x},
$$

where $\partial K_{\mathrm{baro}}^{\prime} / \partial t$ is the time rate of change of the kinetic energy through the barotropic energy conversion, $(\bar{u}, \bar{v})$ are the background zonal and meridional winds, and $\left(u^{\prime}, v^{\prime}\right)$ are the synoptic zonal and meridional wind components. The four terms on the right-hand side are, respectively, the barotropic energy conversion associated with the meridional shear of zonal wind, the zonal convergence of zonal wind, and the meridional convergence of meridional flow, the zonal shear of meridional flow. In the calculation of the barotropic energy conversion, we separate the background flow into seasonal mean and intraseasonal flows to compare their relative contributions. To calculate the different terms in the above equation, we first obtain the synoptic, intraseasonal, and seasonal mean wind component from original daily mean winds. The synoptic wind components are derived using original daily mean minus a 9-day running mean. The intraseasonal wind components are obtained using a 9-day running mean minus a 91-day running mean. Each term on the right-hand side of the above equation is calculated by averaging the product of daily quantities during JJA and SON in a specific year. The terms including both seasonal mean and intraseasonal flows $\left[-u^{\prime} \tilde{v}(\partial \overline{\bar{u}} / \partial y)-u^{\prime} \tilde{u}(\partial \overline{\bar{u}} / \partial x)-v^{\prime} \tilde{\boldsymbol{v}}(\partial \overline{\bar{v}} / \partial y)-v^{\prime} \tilde{u}(\partial \overline{\bar{v}} / \partial x)\right.$ and $-u^{\prime} \overline{\bar{v}}(\partial \tilde{u} / \partial y)-u^{\prime} \overline{\bar{u}}(\partial \tilde{u} / \partial x)-v^{\prime} \overline{\bar{v}}(\partial \tilde{v} / \partial y)-v^{\prime} \overline{\bar{u}}(\partial \tilde{v} / \partial x)$, where the tilde denotes intraseasonal flow and the double overbar denotes seasonal mean flow] are small when averaged over a season and thus they are not considered in the present analysis. Note that the present study only analyzes the barotropic energy conversion from seasonal mean and intraseasonal flows to the synoptic-scale disturbances. The baroclinic energy conversion from the eddy available potential energy, the advection of eddy kinetic energy by seasonal mean and intraseasonal flows, and the generation of eddy kinetic energy through the convergence of the perturbation geopotential flux are not analyzed. For example, the effect of the vertical shear of winds is ignored in the present analysis. For a complete description of the different processes contributing to the tendency of the eddy kinetic energy, the readers may refer to previous studies (e.g., Maloney and Dickinson 2003; Hsu et al. 2011; Wu et al. 2015b).

A composite analysis is conducted to obtain features common to each type of years. For a specific type of years, we obtained the composite mean anomalies and the standard deviation of individual anomalies with respect to the composite mean anomalies. The ratio of the composite mean anomalies to the standard deviation of individual anomalies with respect to the composite mean is used to measure the robustness of the composite mean anomalies. The composite mean denotes the signal and the standard 

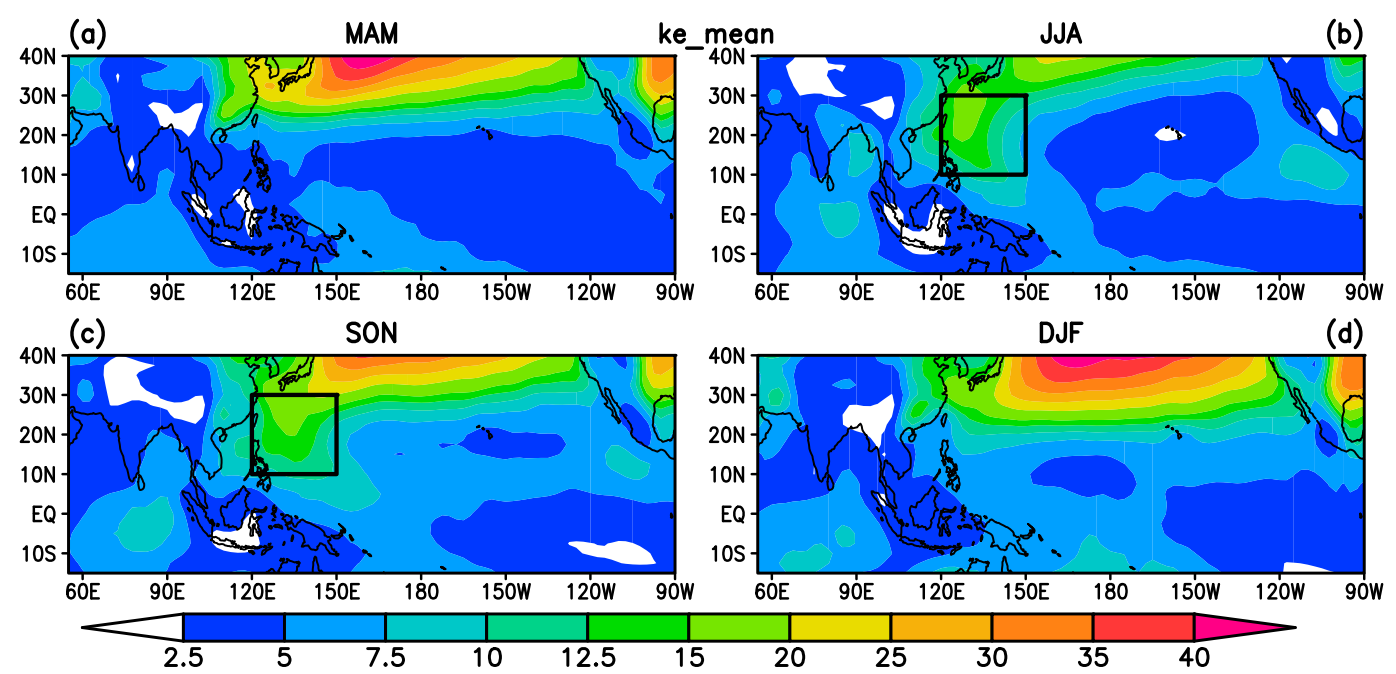

FIG. 1. Mean of kinetic energy $\left(\mathrm{m}^{2} \mathrm{~s}^{-2}\right.$ ) of synoptic-scale wind variations during (a) MAM, (b) JJA, (c) SON, and (d) DJF for the period 1979-2018. The box in (b) and (c) denotes the domain used to define the TWNP intensity index.

deviation represents the noise and the composite mean divided by the standard deviation indicates the signal-to-noise ratio. In the present study, when the above ratio is larger than 1.0, the composite mean anomalies are considered to be statistically significant.

\section{Relation of the intensity of synoptic-scale variability to equatorial Pacific SST}

This section intends to identify the key regions of SST anomalies that may affect the intensity of the SSV over the TWNP through a statistical correlation analysis. This provides a basis for revealing different types of relationships between the intensity of the TWNP SSV and SST anomalies in key regions. Before that, we first document the seasonal features of mean intensity of the SSV and then identify the regions of most prominent year-to-year changes in the intensity of the SSV over the tropical Indo-Pacific region.

The seasonal mean intensity of SSV displays obvious seasonal changes over the tropical Indo-Pacific region. The mean intensity is large in JJA and SON and small in March-May (MAM) and December-February (DJF) (Fig. 1). This is in sharp contrast to the midlatitude North Pacific region where the mean intensity is large in DJF and MAM, but small in SON and JJA. A feature of note is that the mean intensity in JJA and SON is much larger over the TWNP than that in the other regions of the same latitude (Figs. 1b,c). This indicates the importance of the TWNP SSV. We note that the mean intensity based on 3-9-day filtered wind fields displays very similar spatial distribution and seasonal variation except for a smaller magnitude.

The standard deviation of intensity of the SSV shows obvious seasonal change over the tropical Indo-Pacific region as well. The standard deviation in JJA and SON is much larger than that in MAM and DJF (Fig. 2). In contrast, in the midlatitude North Pacific, the standard deviation is much larger in DJF and MAM than in SON and JJA. Compared to the regions of the same latitude, the standard deviation in JJA and SON is very pronounced in the TWNP region (Figs. $2 \mathrm{~b}, \mathrm{c}$ ). Thus, the TWNP is also a region with prominent year-to-year changes in the intensity of the SSV. Again, the standard deviation of the intensity based on 3-9-day filtered wind fields displays very similar features except for a smaller magnitude.

The above analyses reveal that the TWNP is a key region of SSV in both JJA and SON. Here, we calculate the area-mean intensity of SSV averaged over the domain of $10^{\circ}-30^{\circ} \mathrm{N}, 120^{\circ}-$ $150^{\circ} \mathrm{E}$ (termed as TWNP) where both large mean and standard deviation of kinetic energy of synoptic-scale wind variations are observed. The above area-mean intensity can be used as an index to represent the intensity variations over the TWNP. This is confirmed by an empirical orthogonal function (EOF) analysis applied to the kinetic energy of synoptic-scale wind variations in JJA and SON. The large loading of the EOF1 in JJA (with a percent variance of $47.4 \%$; Fig. 3a) is located in the region of large mean and standard deviation of synopticscale kinetic energy in JJA (Figs. 1b and 2b). The large loading of the EOF1 in SON (with a percent variance of $30.1 \%$; Fig. 3b) is close to the region of large mean and standard deviation of synoptic-scale kinetic energy in SON (Figs. 1c and 2c). The distribution of EOF1 agrees with that obtained by Zhou et al. (2018) for June-November. The PC1 time series and the intensity index display very consistent year-to-year variations with a correlation coefficient of 0.99 and 0.82 , respectively, in JJA and SON (Figs. 3c,d).

We perform a correlation analysis to identify the key regions of SST anomalies related to the year-to-year changes in the intensity of the TWNP SSV. The correlation analysis is performed for JJA and SON separately. The distribution of SST correlation displays notable differences corresponding to JJA and SON SSV. In JJA, a large positive correlation of SST is detected in the Niño-3.4 region $\left(5^{\circ} \mathrm{S}-5^{\circ} \mathrm{N}, 170^{\circ}-120^{\circ} \mathrm{W}\right)$ with the correlation coefficient exceeding 0.6 in the center (Fig. 4a). The SST in this region is often used as a measure of ENSO. 

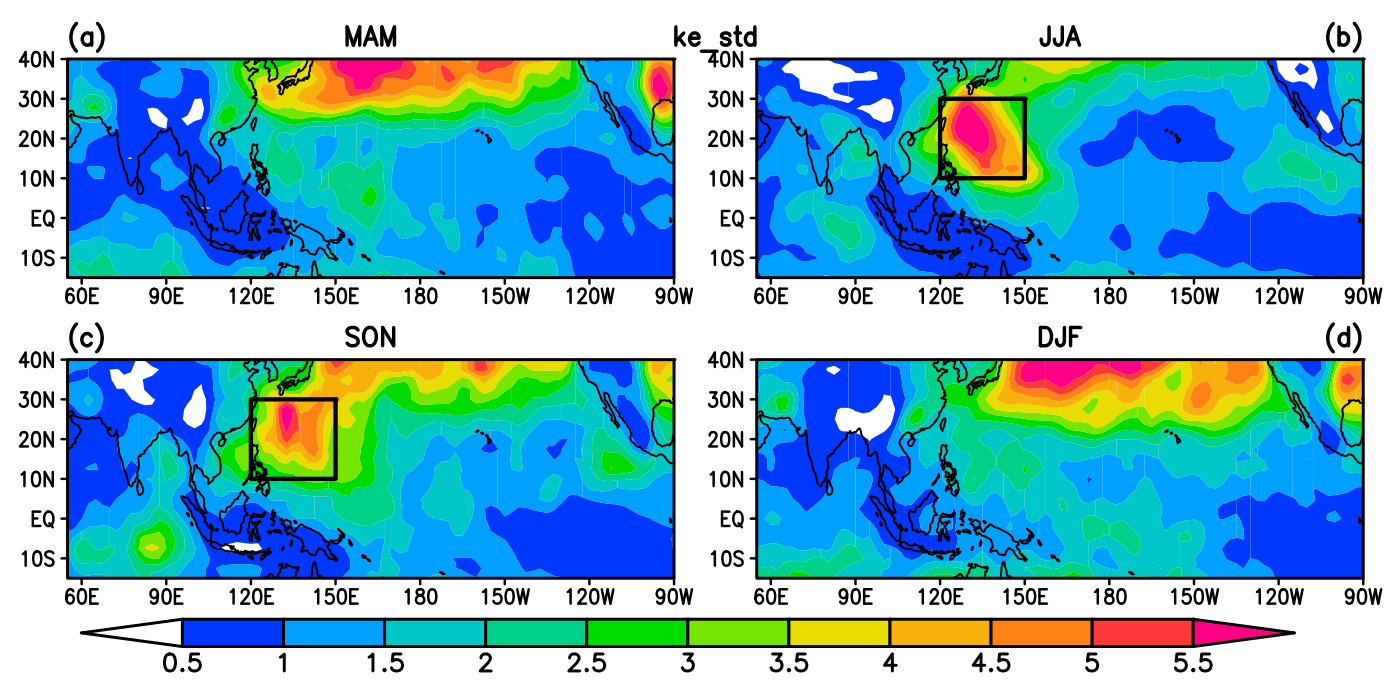

FIG. 2. Standard deviation of kinetic energy $\left(\mathrm{m}^{2} \mathrm{~s}^{-2}\right)$ of synoptic-scale wind variations during (a) MAM, (b) JJA, (c) SON, and (d) DJF for the period 1979-2018. The box in (b) and (c) denotes the domain used to define the TWNP intensity index.

This indicates a close relationship between the intensity of the TWNP SSV in JJA and ENSO. A large negative correlation of SST covers the Philippine Sea and the South China Sea. In SON, a positive correlation of SST is observed in the tropical central Pacific with a large meridional extension, whereas the correlation is relatively small in the equatorial eastern Pacific (Fig. 4b). A negative correlation is observed in the subtropical western North Pacific. The difference in the SST correlation confirms the necessity of analyzing the factors of changes in the intensity of the SSV during JJA and SON separately. We note
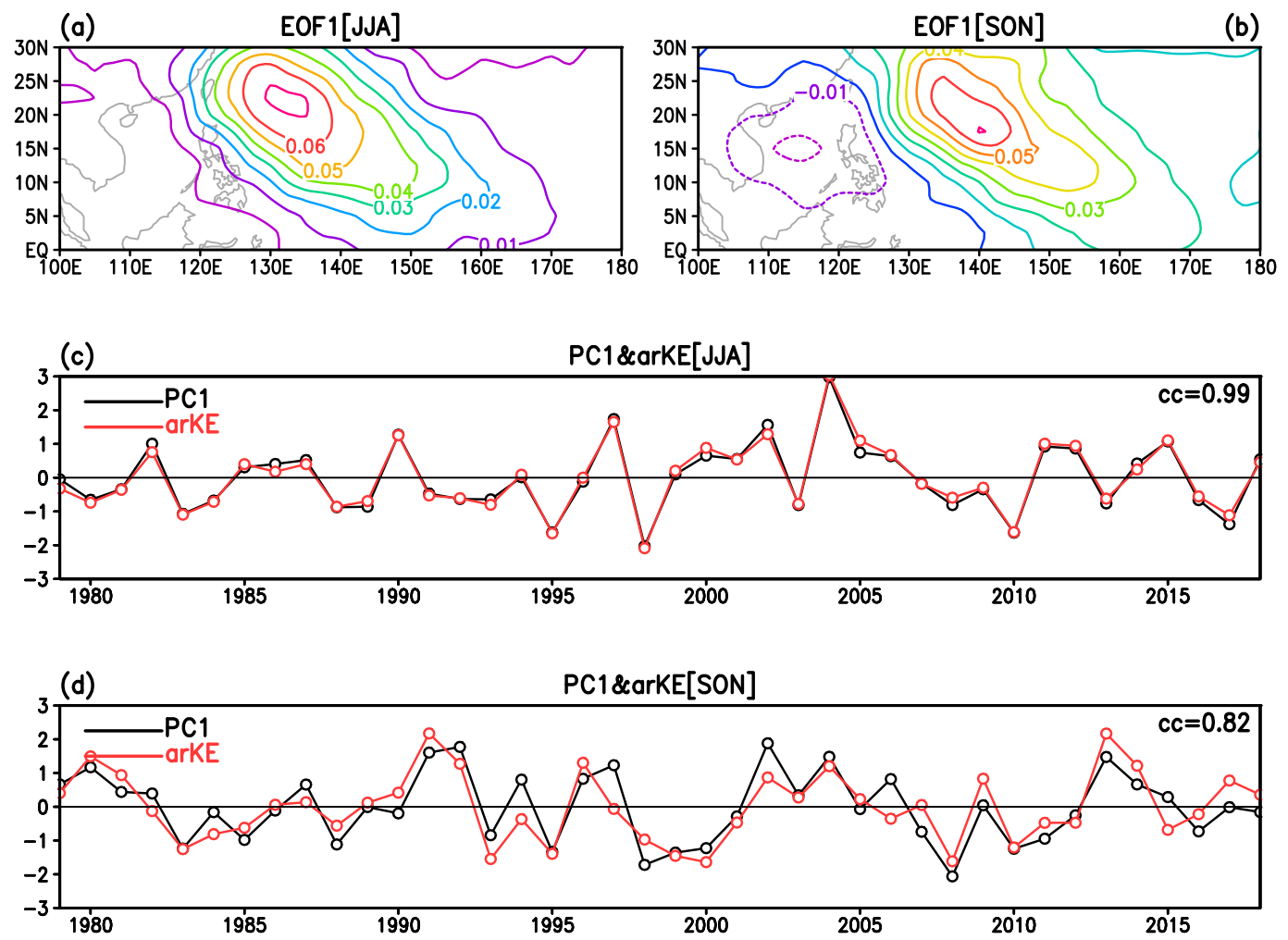

FIG. 3. The EOF1 of kinetic energy of synoptic-scale wind variations in (a) JJA and (b) SON for the period 1979-2018. (c) The PC1 time series (black curve) and normalized TWNP intensity index (red curve) in JJA during 1979-2018. (d) The PC1 time series (black curve) and normalized TWNP intensity index (red curve) in SON during 1979-2018. The numbers in the top right of (c) and (d) are the correlation coefficients. 

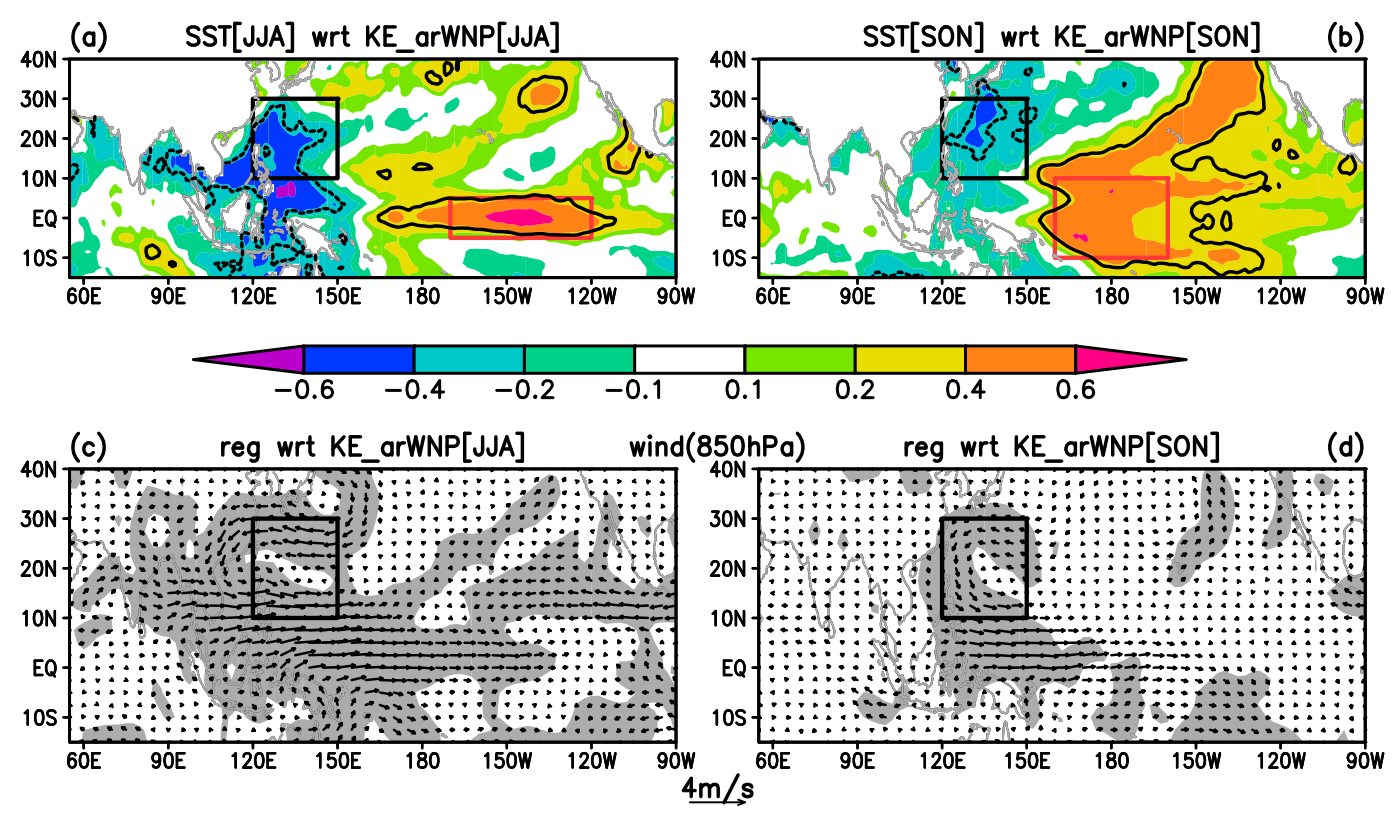

FIG. 4. Concurrent correlation of SST with the TWNP intensity index in (a) JJA and (b) SON for the period 1979-2018. The 850-hPa wind anomalies ( $\mathrm{m} \mathrm{s}^{-1}$; scale at the middle bottom) in (c) JJA and (d) SON obtained by regression with respect to concurrent area-mean TWNP intensity index during 1979-2018. The black boxes denote the domain used to define the TWNP intensity index. The red boxes in (a) and (b) denote the domain of the Niño-3.4 and ECP region, respectively, used to define the SST index in JJA and SON. Thick contours in (a) and (b) denote that the correlation coefficient is significant at the $95 \%$ confidence level according to the Student's $t$ test. Shading in (c) and (d) denotes wind anomalies significant at the $95 \%$ confidence level according to the Student's $t$ test.

that the negative correlation in the Philippine Sea in JJA and in the subtropical western North Pacific in SON indicates a response of local SST change to the enhanced synoptic-scale disturbances. This is confirmed by an analysis of lead-lag correlation between area-mean kinetic energy (KE) and SST averaged over the TWNP. The SST correlation with respect to JJA (SON) KE is very weak before July (September) and drops sharply to a large negative correlation $(<-0.5)$ in July (September) (figures not shown). The effect of synoptic-scale disturbance is likely through surface latent heat flux. Over the TWNP where easterly trade winds and monsoon westerlies converge, seasonal mean winds are weak. Under the weak background winds, synoptic-scale wind disturbances enhance surface latent heat flux in both the westerly and easterly phases and the accumulated latent heat flux contributes to the SST decrease $(\mathrm{Wu}$ et al. 2020a,b; Wang et al. 2020). The difference in the region of SST anomalies is related to that in the lower-level wind anomalies that modulate the intensity of the TWNP SSV. The cyclonic wind anomalies corresponding to enhanced TWNP SSV are stronger and have a larger spatial coverage in JJA than in SON (Figs. 4c,d). In particular, significant anomalous westerlies extend eastward to $135^{\circ} \mathrm{W}$ along the equatorial Pacific in JJA (Fig. 4c), but are confined to west of $150^{\circ} \mathrm{W}$ in SON (Fig. 4d). This difference suggests that the intensity of the TWNP SSV is affected by the SST anomalies with a larger eastward extension along the equatorial Pacific in JJA, but has a weak relation to the SST anomalies in the equatorial eastern Pacific in fall.

To examine details of the relationship between the intensity of the TWNP SSV and the equatorial Pacific SST, we compare the year-to-year changes in area-mean intensity of SSV averaged over the TWNP in JJA with those in the Niño-3.4 SST anomalies in JJA (Fig. 5a). Similarly, we compare the year-toyear changes in area-mean intensity of SSV averaged over the TWNP in SON with those in area-mean SST anomalies averaged over the domain of $10^{\circ} \mathrm{S}-10^{\circ} \mathrm{N}, 160^{\circ} \mathrm{E}-160^{\circ} \mathrm{W}$ [referred to as the equatorial central Pacific (ECP)] where a large positive correlation is detected in SON (Fig. 5b). The correlation coefficient between the intensity index and the SST index is 0.52 in JJA and 0.55 in SON for the period 1982-2018. Although the above correlation coefficients reach the $99 \%$ confidence level, the percent variance of the intensity of the TWNP SSV accounted for by the regional SST anomalies is not high based on the correlation coefficient. This implies that there are other factors contributing largely to the year-to-year changes in the intensity of the TWNP SSV. We note that the correlation of the intensity of the TWNP SSV in SON with the Niño-3 $\left(5^{\circ} \mathrm{S}-5^{\circ} \mathrm{N}, 120^{\circ}-90^{\circ} \mathrm{W}\right) \mathrm{SST}$ is only 0.23 , consistent with that in Fig. 4b. In particular, there are a few years $(1982,1987,1997,2007,2015$, and 2017) in which large Niño-3 SST anomalies are accompanied by small or opposite anomalies in the TWNP intensity index (Fig. 5b). This explains why the TWNP intensity index in SON has a small positive correlation with the SST anomalies in the equatorial eastern Pacific (Fig. 4b). Here, we want to point out that the TWNP intensity index defined based on 3-9-day filtered wind fields displays almost identical year-to-year changes (with a correlation coefficient of 0.99 for both JJA and SON) except for a smaller magnitude.

Inspection of the year-to-year variations of the TWNP intensity and Niño-3.4 or ECP SST index reveals that there 

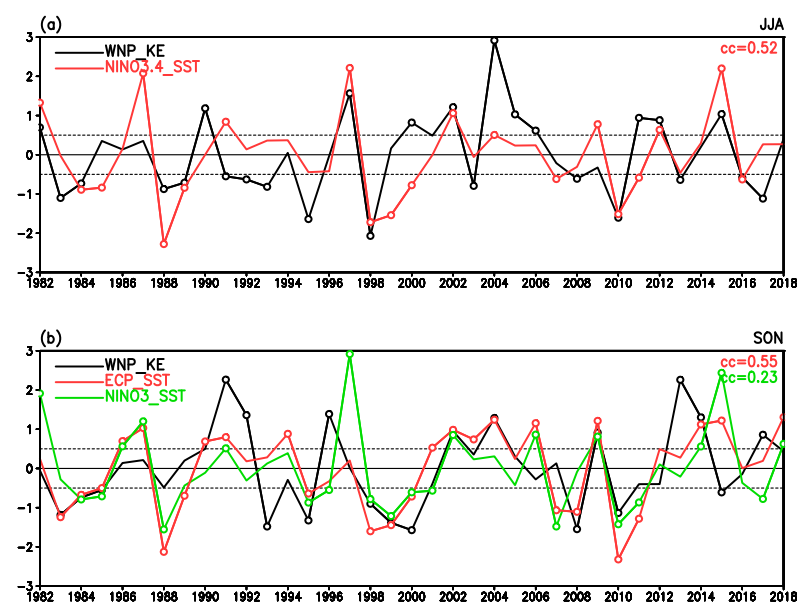

FIG. 5. (a) The normalized TWNP intensity index (black curve) and Niño-3.4 SST index (red curve) in JJA during 1979-2018. (b) The normalized TWNP intensity index (black curve) and ECP SST index (red curve) and Niño-3 SST index (green curve) in SON during 19792018. The dashed horizontal lines denote the 0.5 standard deviation value. Marked points denote that the value exceeds the 0.5 standard deviation. The numbers in the top right are the correlation coefficients.

are different types of relationships between them. It is necessary to distinguish the different types of relationships and analyze and compare the anomalies in these different types of years to reveal the factors of large TWNP intensity changes. Here, we determine a large or small intensity or SST index based on respective 0.5 standard deviation. In JJA, there are 12 years when large TWNP intensity anomalies appear with same-sign Niño-3.4 SST anomalies (Table 1). There are 11 years when large TWNP intensity anomalies are observed with small Niño-3.4 SST anomalies. In addition, there are 5 years when the TWNP intensity anomalies are small although there are El Niño or La Niña events. In SON, there are 14 years when large TWNP intensity anomalies accompany same-sign ECP SST anomalies (Table 2). There are 4 years when large TWNP intensity anomalies are observed with small ECP SST anomalies. There are 12 years when the TWNP intensity anomalies are small although there are large positive or negative ECP SST anomalies.

The above statistics illustrates the complexity in the relationship between the intensity of the TWNP SSV and equatorial Pacific SST anomalies. A correlation analysis may not be able to unravel the different types of relationship. Thus, a detailed examination of anomalies in different types of years is required to provide a comprehensive view of the relationship and understand the factors of the changes in the intensity the TWNP SSV, which is provided in the next two sections for JJA and SON, respectively.

\section{Factors of changes in the intensity of synoptic-scale variability during summer}

In this section, we perform a composite analysis of anomalies in different types of years obtained based on a comparison of the JJA TWNP intensity index and the Niño-3.4 SST index. Three types of years are considered in the composite analysis (Table 1): 1) large intensity with high Niño-3.4 SST or small intensity with low Niño-3.4 SST, 2) large or small intensity with normal Niño-3.4 SST, and 3) normal intensity with high or low Niño-3.4 SST. We analyze first the composite anomalies in the type of years of large TWNP intensity anomalies with the same sign Niño-3.4 SST anomalies, followed by those in the type of years of large TWNP intensity anomalies with small Niño-3.4 SST anomalies, and then those in the type of years of small TWNP intensity anomalies. A parallel composite analysis has been performed with the 0.8 standard deviation as the criterion. The obtained anomalies display very similar spatial distributions with some differences in the magnitude of anomalies.

The first type of years includes six large and six small TWNP intensity years, respectively (Table 1). In the type of years of large TWNP intensity and high Niño-3.4 SST, prominent low-level westerly wind anomalies extend northwestward from the equatorial central Pacific to the Indochina Peninsula with an anomalous cyclone to the north side (Fig. 6a). These wind anomalies indicate an eastward displacement of the monsoon trough. Previous studies have demonstrated that the changes in the monsoon trough play an important role in modulating the synoptic-scale disturbances over the TWNP (Chen and Weng 1998; Wu et al. 2015a,b, 2018). This is accompanied by anomalous easterly shear of zonal wind and ascent that extend northwestward as well (Figs. 6c,e). Anomalous westerly shear of zonal wind is observed along $20^{\circ}-30^{\circ} \mathrm{N}$ from eastern China to the western Pacific (Fig. 6c). The above anomalies indicate a favorable condition for enhanced synoptic-scale activity both in the source region and along the propagation path. In the type of years of small TWNP intensity and low Niño-3.4 SST, nearly opposite anomalies are observed in lower-level wind, vertical shear of zonal wind, and vertical motion with a similar spatial distribution (Figs. 6b,d,f). These anomalies suppress the synoptic-scale activity in the region from the equatorial central Pacific to the TWNP.

The above background field changes are attributed to the SST anomalies in the tropical Indo-Pacific region. In the type of years of large TWNP intensity and high Niño-3.4 SST, positive SST anomalies cover the equatorial central-eastern Pacific (Fig. 6a). Negative SST anomalies are observed in the equatorial western Pacific and tropical southeastern Indian Ocean. The positive equatorial central-eastern SST anomalies induce the low-level cyclonic wind anomalies over the TWNP through a Rossby wave response. In addition, the negative SST

TABLE 1. Types of years based on JJA TWNP KE and JJA Niño-3.4 SST anomalies.

\begin{tabular}{lccr}
\hline \multicolumn{1}{c}{ Type } & High SST & Normal SST & Low SST \\
\hline Large KE & $1982,1997,2002,2004,2012,2015$ & $1990,2005,2006$ & 2000,2011 \\
Small KE & 1991 & $1983,1992,1993,1995,2003,2008,2013,2017$ & $1984,1988,1989,1998,2010,2016$ \\
Normal KE & 1987,2009 & $1986,1994,1996,2001,2014,2018$ & $1985,1999,2007$ \\
\hline
\end{tabular}


TABLE 2. Types of years based on SON TWNP KE and SON ECP SST anomalies.

\begin{tabular}{lccc}
\hline \multicolumn{1}{c}{ Type } & High SST & Normal SST & Low SST \\
\hline Large KE & $1991,2002,2004,2009,2014$ & $1992,1996,2013,2017$ & - \\
Small KE & 2015 & 1993 & $1983,1984,1985,1995,1998,1999,2000$, \\
& & & 2008,2010 \\
Normal KE & $1986,1987,1990,1994,2001,2003$, & $1982,1997,2005,2012,2016$ & $1988,1989,2007,2011$ \\
& 2006,2018 & & \\
\hline
\end{tabular}

anomalies in the tropical southeastern Indian Ocean can have a supplementary role through an anomalous cross-equatorial overturning circulation based on previous observational analysis and numerical model experiment (R. Wu et al. 2012; He and $\mathrm{Wu}$ 2014). This point of view is supported by a contrast of anomalous vertical motion between the tropical southeastern Indian Ocean and the Philippine Sea (Fig. 6e). The above arguments work as well in the type of years of small TWNP intensity and low Niño3.4 SST except for a reversal of sign of anomalies.

The second type of years includes three large and eight small TWNP intensity years, respectively (Table 1). Here, we only analyze anomalies in the small intensity years as the number of cases is too small in the large intensity years. Anomalies of low-level wind, vertical shear of zonal wind, and vertical motion are weak over the equatorial central-eastern Pacific (Figs. 7a-c). Anomalous low-level anticyclonic winds and descent are confined to the TWNP and weak anomalous easterly shear is limited to the equatorial western Pacific. Since the SST anomalies are weak in the tropical Indo-Pacific region (Fig. 7a), this suggests that the anomalous anticyclone and descent over the TWNP may be largely attributed to internal atmospheric processes, such as a positive atmospheric
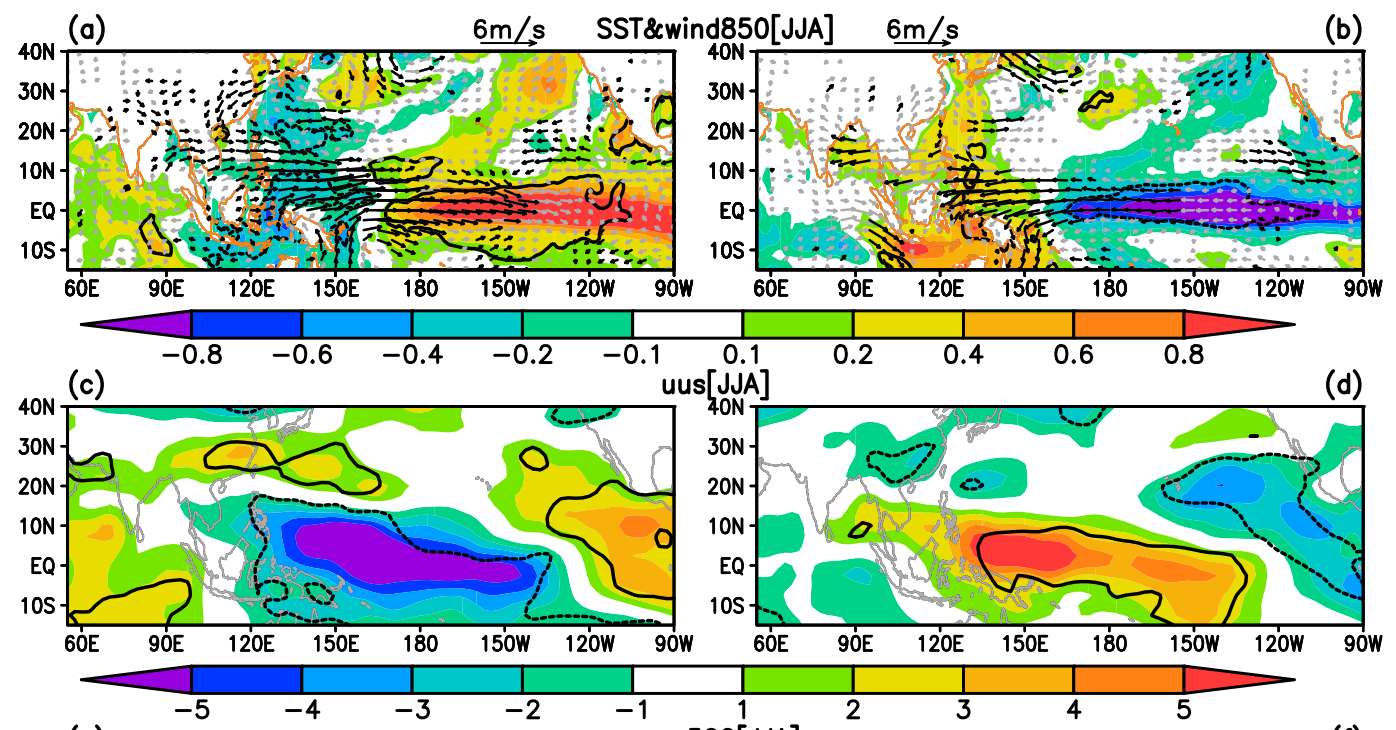

(e) omg500[JJA]

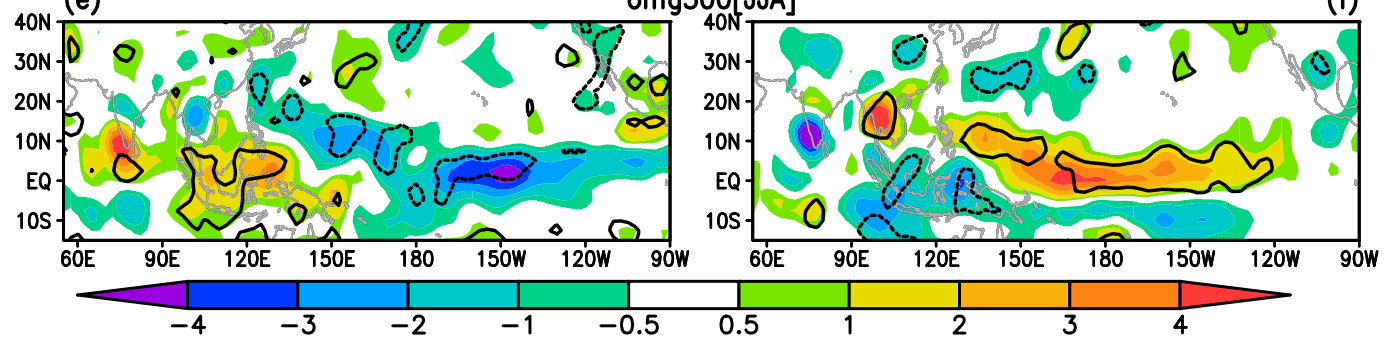

FIG. 6. Composite anomalies of (a),(b) SST (shading; ${ }^{\circ} \mathrm{C}$ ) and $850-\mathrm{hPa}$ wind anomalies (vectors; $\mathrm{m} \mathrm{s}^{-1}$; scale at top), (c),(d) vertical shear of zonal wind $\left(\mathrm{m} \mathrm{s}^{-1}\right)$, and (e),(f) 500-hPa vertical $p$ velocity $\left(10^{-2} \mathrm{~Pa} \mathrm{~s}^{-1}\right)$ in years of (a),(c),(e) large TWNP intensity with high Niño-3.4 SST and (b),(d),(f) small TWNP intensity with low Niño-3.4 SST in JJA. Thick contours denote that the composite mean anomalies are larger than the standard deviation of individual anomalies. Black vectors denote that the length of composite wind anomalies are larger than the magnitude of standard deviation of individual zonal and meridional wind anomalies. Only wind vectors with a magnitude larger than $0.3 \mathrm{~m} \mathrm{~s}^{-1}$ are plotted. 


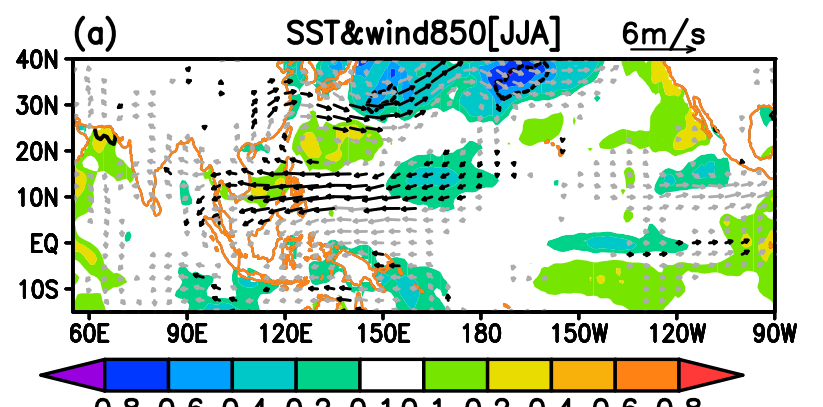

$\begin{array}{llllllll} & 0.8-0.6-0.4-0.2-0.10 .1 & 0.2 & 0.4 & 0.6 & 0.8\end{array}$

(b) uus[JJA]
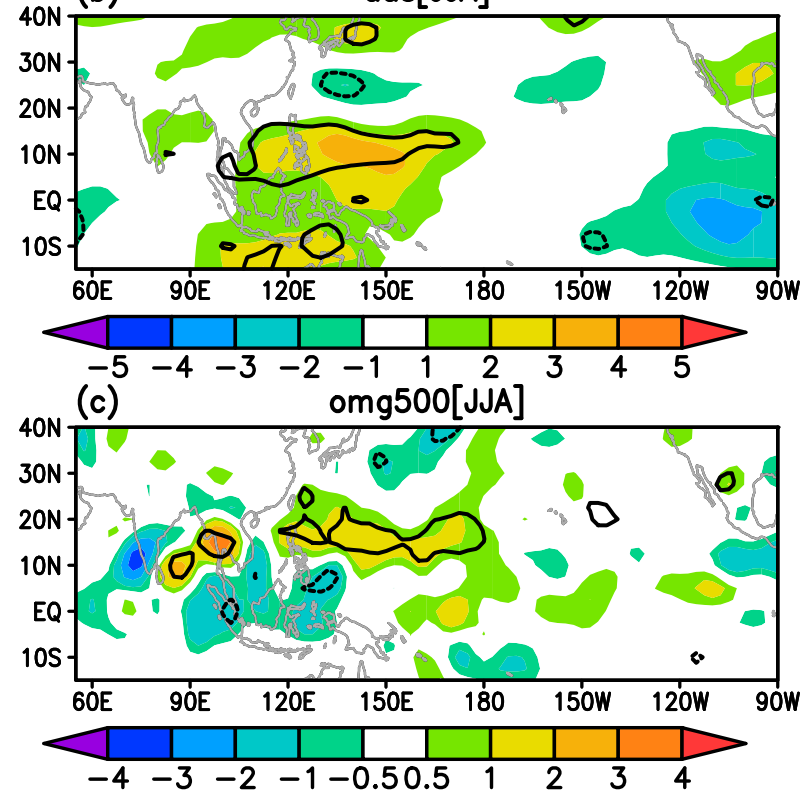

FIG. 7. Composite anomalies of (a) SST (shading; ${ }^{\circ} \mathrm{C}$ ) and 850-hPa wind anomalies (vectors; $\mathrm{m} \mathrm{s}^{-1}$; scale at top), (b) vertical shear of zonal wind $\left(\mathrm{m} \mathrm{s}^{-1}\right)$, and (c) 500 -hPa vertical $p$ velocity $\left(10^{-2} \mathrm{~Pa} \mathrm{~s}^{-1}\right)$ in years of small TWNP intensity with normal Niño-3.4 SST in JJA. Thick contours denote that the composite mean anomalies are larger than the standard deviation of individual anomalies. Black vectors denote that the length of composite wind anomalies are larger than the magnitude of standard deviation of individual zonal and meridional wind anomalies. Only wind vectors with the magnitude larger than $0.3 \mathrm{~m} \mathrm{~s}^{-1}$ are plotted.

circulation-heating feedback. The anomalous descent suppresses condensational heating in the atmosphere that induces a lower-level anticyclone located to the northwest as a Rossby wave response. In turn, anomalous lower-level winds reduce moisture convergence and contribute to descending motion.

The third type of years includes two El Niño or three La Niña events (Table 1). One may ask why large equatorial central-eastern Pacific SST anomalies are not accompanied by notable changes in the intensity of the TWNP SSV in these years. To address this question, we examine composite anomalies in these 5 years. Due to the limited number of cases, we reverse the anomalies in years when the Niño-3.4 SST index is negative and combine with those in years when the Niño-3.4 SST index is positive. The differences of anomalies between positive and negative Niño-3.4 SST index years are not a concern in the following. Large positive SST anomalies are observed in the equatorial central-eastern Pacific, accompanied by low-level anomalous westerlies, anomalous easterly shear of zonal wind, and anomalous ascent over the equatorial central Pacific (Fig. 8). These features are similar to those in the first type of years (Figs. 6a,c,e). An anomalous cyclone extends westward to the South China Sea, but the wind anomalies are insignificant over the equatorial western Pacific. An anomalous anticyclone occupies the subtropical western North Pacific. Positive SST anomalies are present in the north Indian Ocean (Fig. 8a), accompanied by anomalous ascent (Fig. 8c), which indicates a role of SST forcing.

Compared to the first type of years, the equatorial central Pacific SST anomalies appear weaker (Niño-3.4 SST anomalies are $0.85^{\circ} \mathrm{C}$ in the third type of years versus $0.96^{\circ} \mathrm{C}$ in the first type of years) and there are no negative SST anomalies in the equatorial western Pacific and tropical southeastern Indian Ocean (Fig. 8a). As such, the zonal gradient of SST anomalies along the equatorial western Pacific is smaller compared to that in the first type of years. According to Lindzen and Nigam (1987), the smaller SST gradient may explain the weaker low-level westerly wind anomalies, weaker easterly shear anomalies, and weaker anomalous ascent over the equatorial western Pacific. In addition, there is no supplementary contribution of the tropical southeastern Indian Ocean SST anomalies. Consequently, the background fields over the equatorial western Pacific are not as favorable as those in the first type of years. On the other hand, positive SST anomalies in the north Indian Ocean may act as a remote forcing, inducing anomalous anticyclone over the subtropical western North Pacific through a Kevin wave-type response (Xie et al. 2009), which is not favorable to the SSV. The above comparison suggests that the modulating effect of the equatorial central Pacific SST anomalies on the synoptic-scale activity over the TWNP may rely on coexisting SST anomalies in other regions. The importance of combined effects of SST anomalies in different regions in driving atmospheric wind changes over the TWNP has been illustrated by previous numerical experiments (Wu et al. 2019; Yang et al. 2020).

The synoptic-scale disturbance obtains kinetic energy from seasonal mean and intraseasonal background flows (Lau and Lau 1992; Sobel and Maloney 2000; Maloney and Hartmann 2001; Maloney and Dickinson 2003; Chen and Huang 2009; Hsu et al. 2011; L. Wu et al. 2012; Tsou et al. 2014; Cao and Wu 2018; Cao et al. 2018). Here, we compare the relative contributions of the four terms in the equation of barotropic kinetic energy conversion in the first type of years. We compare the contributions of the barotropic energy conversion from seasonal mean and intraseasonal flows.

In the type of years of large TWNP intensity with high Niño-3.4 SST, the first term, which is related to the meridional shear of background zonal wind, and the second term, which is related to the convergence of background zonal wind, have a positive contribution (Figs. 9a,b and 9c,d, respectively; Table 3). The third term, which is related to the convergence of background meridional wind, has a negative contribution (Figs. 9e,f; Table 3). The fourth term, which is related to the zonal shear of 


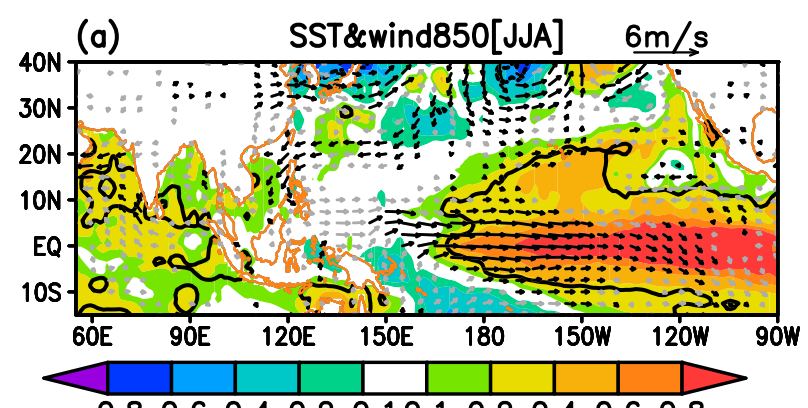

$\begin{array}{lllllllll} & 0.8-0.6-0.4-0.2-0.10 .1 & 0.2 & 0.4 & 0.6 & 0.8\end{array}$

(b)

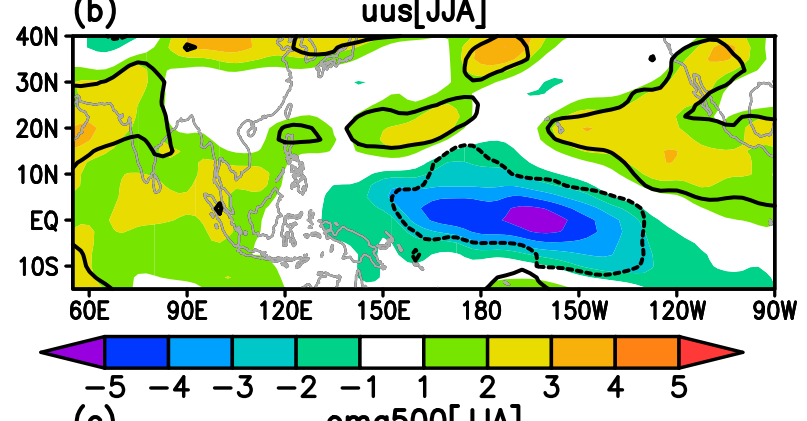

(c) omg500[JJA]

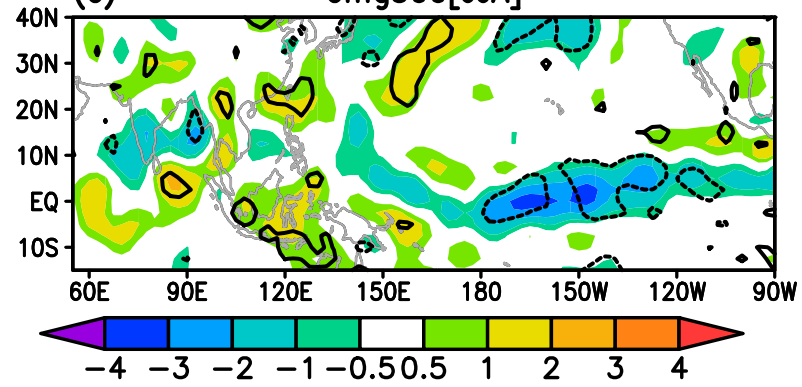

FIG. 8. Composite anomalies of (a) SST (shading; ${ }^{\circ} \mathrm{C}$ ) and 850-hPa wind anomalies (vectors; $\mathrm{m} \mathrm{s}^{-1}$; scale at top), (b) vertical shear of zonal wind $\left(\mathrm{m} \mathrm{s}^{-1}\right)$, and (c) 500 -hPa vertical $p$ velocity $\left(10^{-2} \mathrm{~Pa} \mathrm{~s}^{-1}\right)$ in years of normal TWNP intensity with high Niño-3.4 SST anomaly in JJA. Thick contours denote that the composite mean anomalies are larger than the standard deviation of individual anomalies. Black vectors denote that the length of composite wind anomalies are larger than the magnitude of standard deviation of individual zonal and meridional wind anomalies. Only wind vectors with a magnitude larger than $0.3 \mathrm{~m} \mathrm{~s}^{-1}$ are plotted.

background meridional wind, is small from the seasonal mean flow but has a negative contribution from the intraseasonal flow (Figs. 9g,h; Table 3). These results of the barotropic energy conversion from the seasonal mean background flow are consistent with Zhou et al. (2018), who performed a regression analysis with JJA and SON together. In comparison, the region of large energy conversion from the intraseasonal flow is located at higher latitudes than that from the seasonal mean flow. This is likely due to the northward propagation of intraseasonal signals so that the intraseasonal flow can reach higher latitudes.

In the type of years of small TWNP intensity with low Niño-3.4 SST, the first and second terms are negative (Figs. 10a-d; Table 3). The third term is mainly positive (Figs. 10e,f; Table 3). The fourth term is small from the seasonal mean flow, but is positive from the intraseasonal flow (Figs. 10g,h; Table 3). The region of large conversion from the intraseasonal flow is located at higher latitudes than that from the seasonal mean flow with a comparable magnitude. These features are similar to those in the years of large TWNP intensity except for an opposite sign.

In the second type of years of small TWNP intensity with normal Niño-3.4 SST (figure not shown), the features are mostly similar to the years of small TWNP intensity with low Niño-3.4 SST. In the type of years of large TWNP intensity with normal Niño-3.4 SST and normal TWNP intensity with low Niño-3.4 SST, the intraseasonal flow has a larger contribution than the seasonal mean flow, mainly due to the first and second term, respectively. In the type of years of normal TWNP intensity with normal Niño-3.4 SST, the seasonal mean flow has a larger contribution than the intraseasonal flow.

\section{Factors of changes in intensity of synoptic-scale variability during fall}

In this section, we perform a composite analysis of anomalies in different types of years in SON. Similar to JJA, the types of years are determined based on a comparison of the TWNP intensity index and the ECP SST index in SON. The types of years of composite analysis include those with 1) large TWNP intensity and high ECP SST or small TWNP intensity and low ECP SST, 2) large TWNP intensity with normal ECP SST, and 3) normal TWNP intensity with high and low ECP SST. As in section 4 , the composite anomalies are presented first for the type of years of large TWNP intensity anomalies with same sign ECP SST anomalies, followed by the type of years of large TWNP intensity with small ECP SST anomalies, and then for the type of years with small TWNP intensity anomalies with large ECP SST anomalies.

The first type of years has five large and nine small TWNP intensity years, respectively (Table 2). In the type of years of large TWNP intensity with high ECP SST, the large positive SST anomalies in the equatorial central Pacific induce low-level westerly wind anomalies extending northwestward from the equatorial central Pacific to the Philippines through a Rossby wave response (Fig. 11a). This is accompanied by anomalous easterly shear of zonal wind and ascent that extend northwestward to the Philippine Sea (Figs. 11c,e). The above anomalies indicate a favorable condition for enhanced synoptic-scale activity both in the source region and along the propagation path. In the type of years of small TWNP intensity and low ECP SST, nearly opposite anomalies are observed in lower-level wind, vertical shear of zonal wind, and vertical motion in the tropical Pacific and Indian Oceans (Figs. 11b,d,f). These anomalies are unfavorable for the synoptic-scale activity over the TWNP.

In the second type of years of large TWNP intensity and normal ECP SST (four cases; Table 2), SST anomalies are negative in the equatorial eastern Pacific, positive in the tropical western Pacific, and negative in the tropical Indian Ocean (Fig. 12a). The low-level wind and midlevel vertical motion anomalies along the equator (Figs. 12a,c) are consistent with the above SST anomalies. Negative vertical 

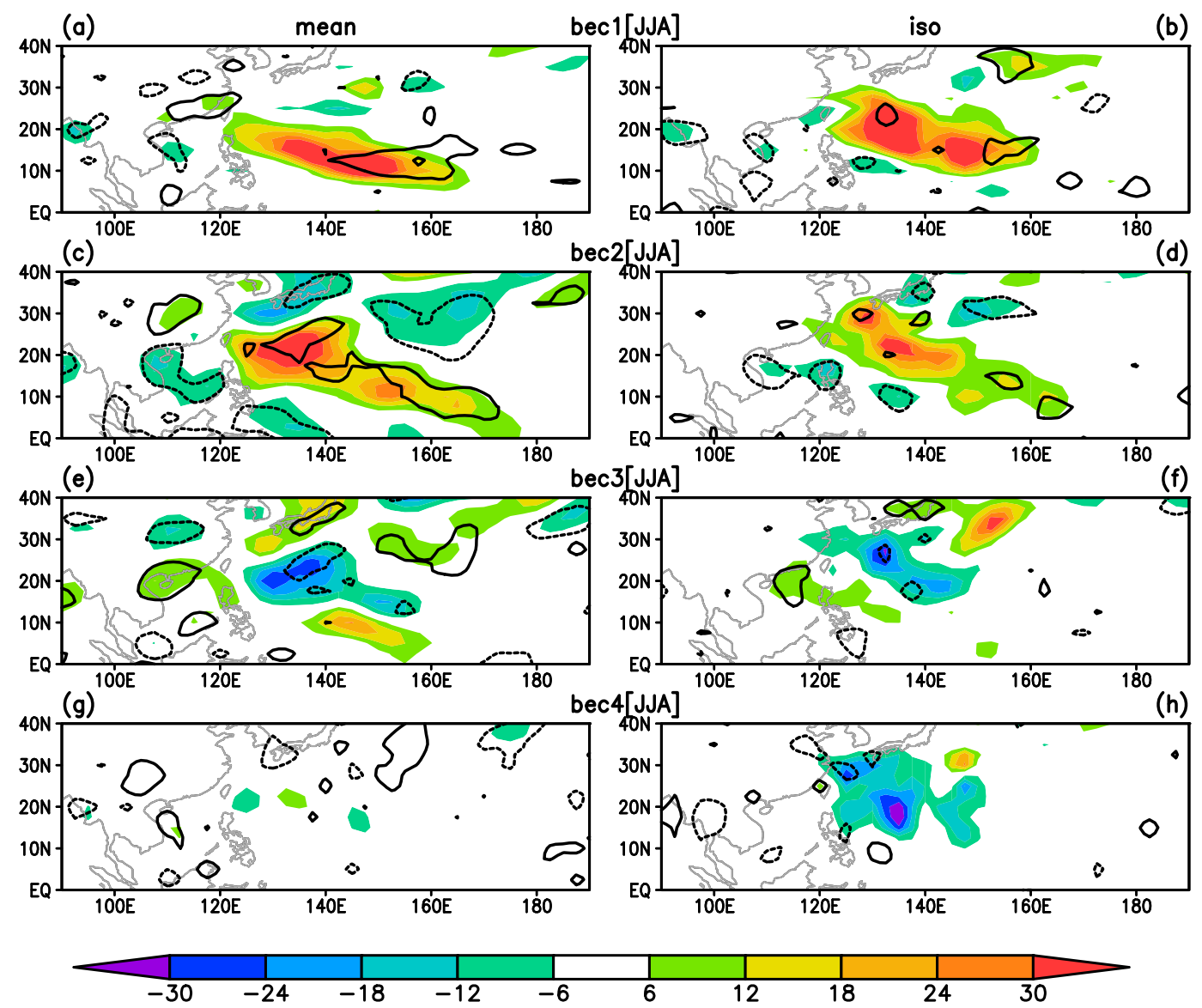

FIG. 9. Composite anomalies $\left(10^{-6} \mathrm{~m}^{2} \mathrm{~s}^{-3}\right)$ of four terms in the equation of barotropic kinetic energy conversion in years of large TWNP intensity with high Niño-3.4 SST associated with (a),(c),(e),(g) seasonal mean and (b),(d),(f),(h) intraseasonal flows in JJA. Thick contours denote that the composite mean anomalies are larger than the standard deviation of individual anomalies. (top to bottom) The terms related to the meridional shear of mean zonal wind, the convergence of mean zonal wind, the convergence of mean meridional wind, and the zonal shear of mean meridional wind, respectively.

shear anomalies are observed over the low-latitude western North Pacific (Fig. 12b). Low-level cyclonic wind anomalies and anomalous ascent are observed over the TWNP (Figs. 12a,c), which are favorable to enhanced SSV. These anomalies are likely contributed by positive SST anomalies in the tropical western Pacific through a Rossby wave-type response. The area-mean SST anomalies averaged in the region of $0^{\circ}-10^{\circ} \mathrm{N}$, $135^{\circ}-165^{\circ} \mathrm{E}$ in fall are above 0.5 standard deviations with the same sign as the intensity index except for one year (1992). The region of background fields favorable to the enhanced synoptic-scale activity is located westward in the second type of years compared to that in the first type of years.

The positive SST anomalies extend from $160^{\circ} \mathrm{E}$ to the coast of South America in the first type of years (Fig. 11a), whereas the negative SST anomalies are confined to east of the date line in the second type of years (Fig. 12a). As such, area-mean SST anomalies in the ECP region are large positive in the first type of years and small in the second type of years (Fig. 5b). In the equatorial eastern Pacific, the SST anomalies are opposite in the two types of years, which explains why the correlation of
SST with the TWNP intensity index is small in the equatorial eastern Pacific (Niño-3) region (Fig. 4b).

The third type of years includes eight high and four low ECP SST years (Table 2). To understand the reason why large equatorial central Pacific SST anomalies are not accompanied by notable changes in the intensity of the TWNP SSV in these

TABLE 3. Area-mean composite anomalies $\left(10^{-6} \mathrm{~m}^{2} \mathrm{~s}^{-3}\right)$ of four terms in the equation of barotropic kinetic energy conversion in years of large TWNP intensity with high Niño-3.4 SST and small TWNP KE intensity with low Niño-3.4 SST in JJA.

\begin{tabular}{|c|c|c|c|c|}
\hline \multirow[b]{2}{*}{ Type } & \multicolumn{2}{|c|}{ Large KE-high SST } & \multicolumn{2}{|c|}{ Small KE-low SST } \\
\hline & $\begin{array}{l}\text { Mean } \\
\text { flow }\end{array}$ & $\begin{array}{c}\text { Intraseasonal } \\
\text { flow }\end{array}$ & $\begin{array}{l}\text { Mean } \\
\text { flow }\end{array}$ & $\begin{array}{c}\text { Intraseasonal } \\
\text { flow }\end{array}$ \\
\hline Term 1 & 10.43 & 16.22 & -6.66 & -10.08 \\
\hline Term 2 & 13.57 & 9.07 & -9.83 & -7.34 \\
\hline Term 3 & -5.46 & -4.34 & 4.63 & 4.13 \\
\hline Term 4 & -1.05 & -9.74 & -0.67 & 4.35 \\
\hline
\end{tabular}



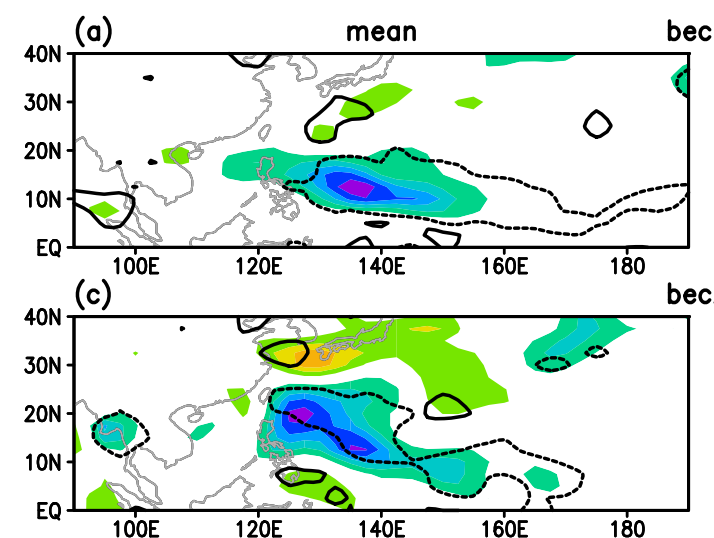

bec2[JJA]
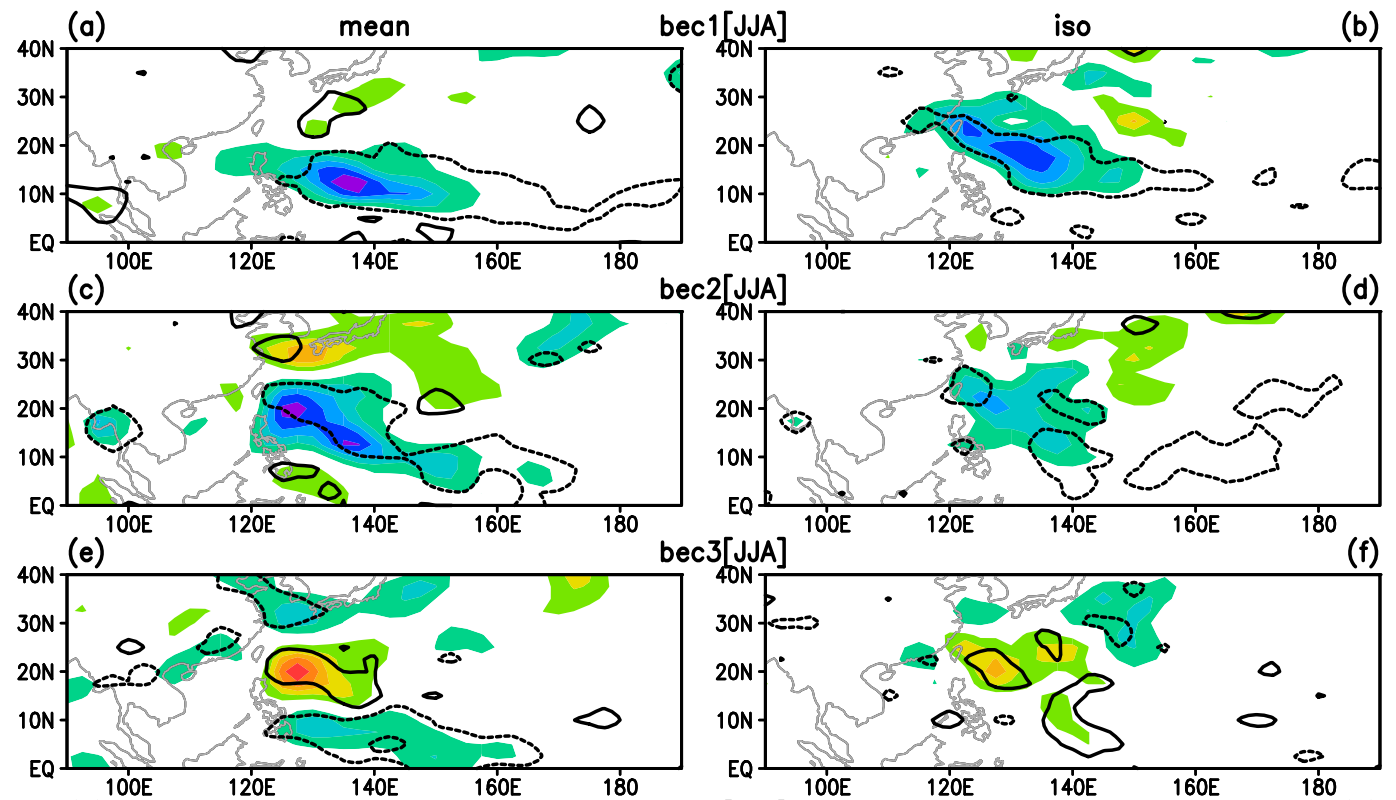

ec3[JJA]
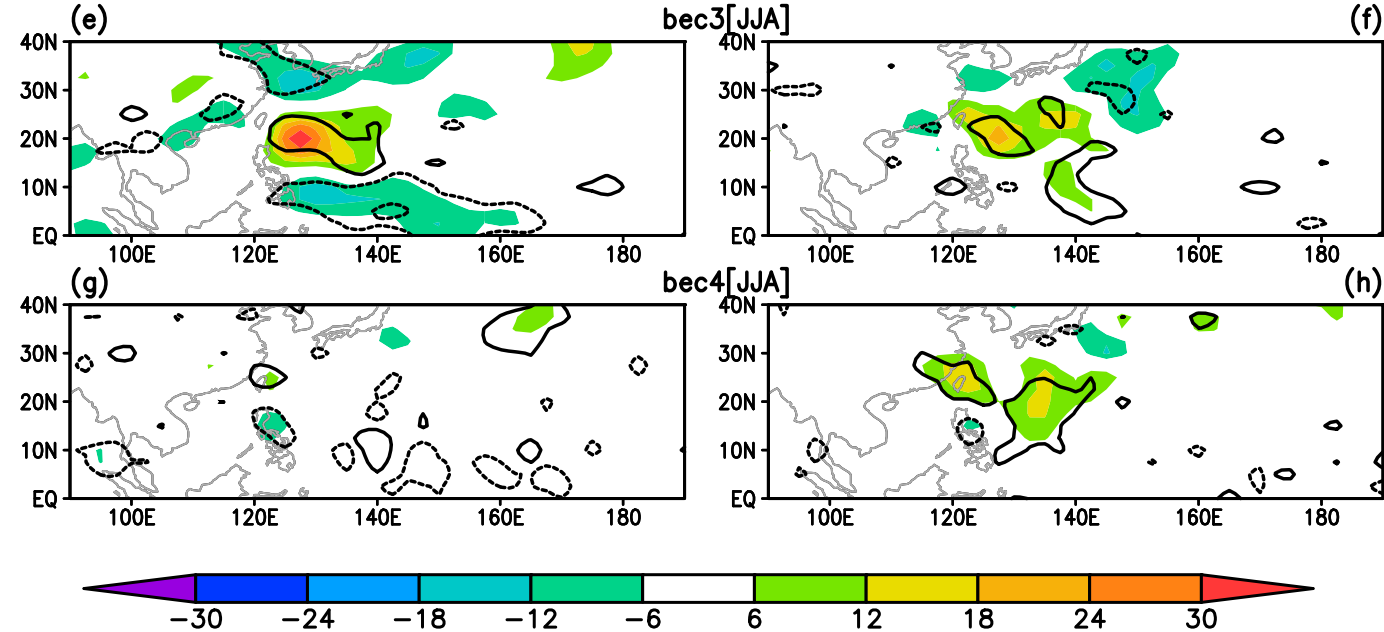

FIG. 10. As in Fig. 9, but in years of small TWNP intensity with low Niño-3.4 SST.

years, we examine composite anomalies for these 12 years. In the years of high ECP SST, large positive SST anomalies in the equatorial central Pacific are accompanied by anomalous low-level westerlies, easterly vertical shear, and ascent (Figs. 13a,c,e). Anomalous descent is observed over the equatorial western Pacific (Fig. 13e). However, anomalies of low-level wind, vertical shear, and vertical motion are all weak over the TWNP. This explains why there are no notable anomalies in the intensity of the SSV over the TWNP in these years. In the years of low ECP SST, large negative SST anomalies are observed in the equatorial central-eastern Pacific (Fig. 13b). Anomalous lower-level easterlies, westerly vertical shear and descent cover the equatorial central Pacific (Figs. 13b,d,f) and anomalous ascent is present over the equatorial western Pacific (Fig. 13f). Anomalies of low-level wind and vertical shear are small over the TWNP (Figs. 13b,d). Accordingly, there are no notable anomalies in the intensity of the SSV over the TWNP in these years.

Comparing the SST anomalies with those in the first type of years (Fig. 11a), a prominent feature is the absence of negative SST anomalies in the TWNP region (Fig. 13a). Consequently, the gradient of SST anomalies in the tropical western Pacific is smaller than that in the first type of years. This accounts for why the low-level westerly wind anomalies and anomalous ascent cannot extend northwestward to the TWNP (Figs. 13a,c). The above difference suggests a supporting role of the TWNP SST anomalies in the influence of the equatorial central Pacific SST anomalies to induce large changes in the intensity of the SSV over the TWNP. As noted in section 3, the negative TWNP SST anomalies may be partly contributed by the enhanced SSV over the TWNP. This suggests an interaction over the TWNP. On one hand, the enhanced synoptic-scale activity induced by remote SST forcing contributes to local SST cooling. On the other hand, the local SST cooling increases the zonal SST contrast that favors the northwestward extension of anomalous winds to the TWNP, which modulates the background of the synoptic-scale activity over the TWNP.

To understand the formation of different SST anomaly patterns, we have compared the temporal evolution of composite SST and lower-level wind anomalies in the first and third types of years. In the first types of years, positive/negative SST anomalies are observed around the date line in preceding MAM and are maintained and extend eastward with an intensification in preceding JJA (figures not shown). This is accompanied by an anomalous lower-level cyclone/anticyclone over the TWNP. The anomalous TWNP cyclone/anticyclone provides a favorable condition for the development of negative/positive SST anomalies in the TWNP through cloud-radiation and wind-evaporation 

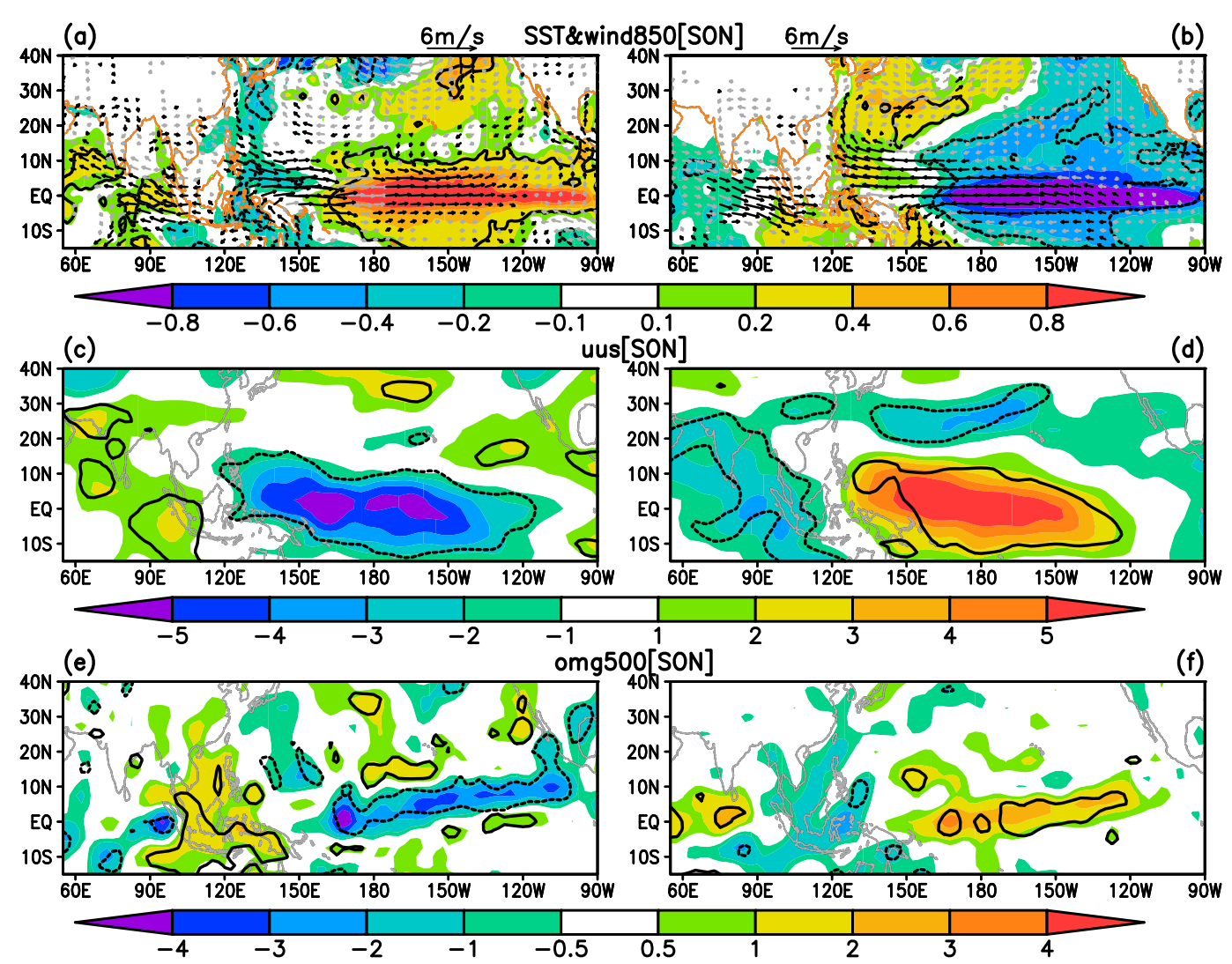

FIG. 11. Composite anomalies of (a),(b) SST (shading; ${ }^{\circ} \mathrm{C}$ ) and $850-\mathrm{hPa}$ wind anomalies (vectors; $\mathrm{m} \mathrm{s}^{-1}$; $\mathrm{scale}$ at top), (c),(d) vertical shear of zonal wind $\left(\mathrm{m} \mathrm{s}^{-1}\right)$, and (e),(f) 500-hPa vertical $p$ velocity $\left(10^{-2} \mathrm{~Pa} \mathrm{~s}^{-1}\right)$ in years of (a),(c),(e) large TWNP intensity with high ECP SST and (b),(d),(f) small TWNP intensity with low ECP SST in SON. Thick contours denote that the composite mean anomalies are larger than the standard deviation of individual anomalies. Black vectors denote that the length of composite wind anomalies are larger than the magnitude of standard deviation of individual zonal and meridional wind anomalies. Only wind vectors with a magnitude larger than $0.3 \mathrm{~m} \mathrm{~s}^{-1}$ are plotted.

effects as documented by previous studies (Wang et al. 2003; R. $\mathrm{Wu}$ et al. 2014). The anomalous TWNP cyclone (anticyclone) also enhances (weakens) the high-frequency wind disturbances over the TWNP according to previous studies (Wu et al. 2015a,b; Wu and Song 2018). The latent heat flux related to high-frequency wind variations may accumulate and contribute to the development of negative/positive SST anomalies there (Wu et al. 2020a,b; Wang et al. 2020). Consequently, an east-west SST anomaly pattern forms in SON. In the third type of years, the SST anomalies are either weak or located too far eastward along the equatorial Pacific in preceding MAM and JJA. Accordingly, the lower-level wind anomalies are confined to the equatorial region, but weak over the TWNP. Consequently, the atmospheric effect on ocean is relatively small in the TWNP. This explains why no notable SST anomalies form over the TWNP in SON. The above comparison suggests that the difference in SST and wind anomalies in SON is related to the location of equatorial Pacific SST anomalies in preceding seasons. Further examination of SST anomalies in individual cases of the two types of years tells that the location of equatorial Pacific SST anomalies in preceding seasons may be a factor for the development of the TWNP SST anomalies, but not for all the cases.

The spatial distribution of different terms of barotropic kinetic energy conversion displays notable differences. In the type of years of large TWNP intensity with high Niño-3.4 SST, the first and second terms have a positive contribution from the seasonal mean flow with the first term larger than the second term at lower latitudes and the second term extending to higher latitudes (Figs. 14a,c). Based on the area-mean anomalies over the TWNP, the second term is somewhat larger (Table 4). The third term has a negative contribution from the seasonal mean flow (Fig. 14e; Table 4) and the fourth term associated with the seasonal mean flow is small (Fig. 14g; Table 4). The terms associated with the intraseasonal flow tend to display small-scale features with alternative positive and negative contributions (Figs. 14b,d,f,h). As such, the area-mean anomalies are small for these terms (Table 4).

In the type of years of small TWNP intensity with low Niño-3.4 SST, the first and second terms are negative in association with the seasonal mean flow (Figs. 15a,c; Table 4). The third term associated with the seasonal mean flow is mainly positive (Fig. 15e; 


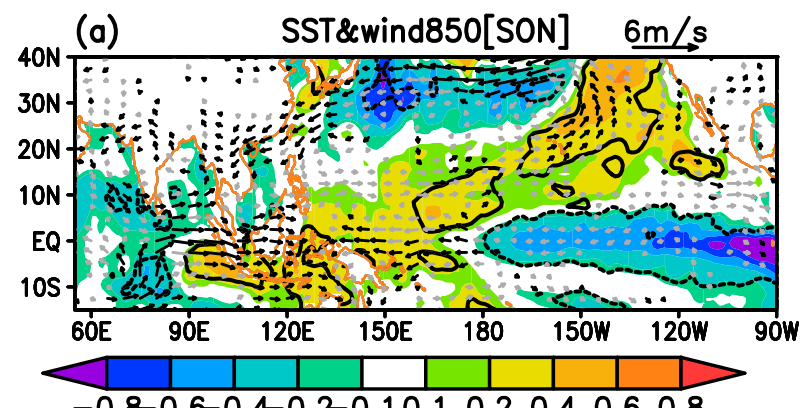

$\begin{array}{lllllllllll} & 0.8-0.6-0.4-0.2-0.10 .1 & 0.2 & 0.4 & 0.6 & 0.8\end{array}$

(b)

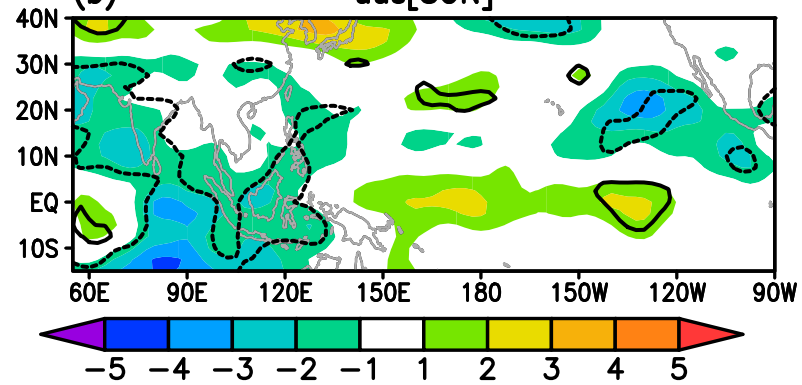

(c)

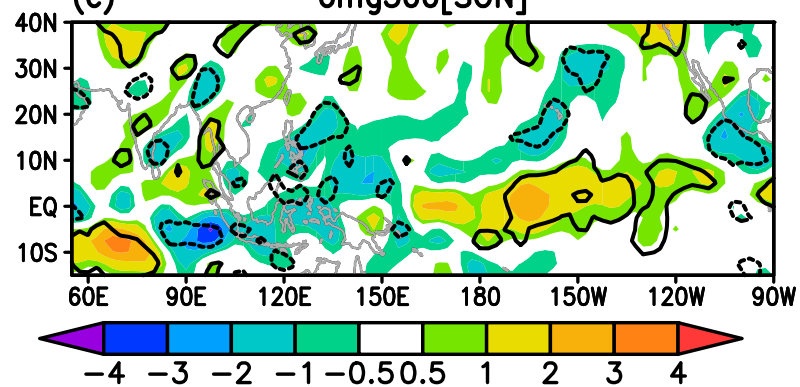

FIG. 12. Composite anomalies of (a) SST (shading; ${ }^{\circ} \mathrm{C}$ ) and 850-hPa wind anomalies (vectors; $\mathrm{m} \mathrm{s}^{-1}$; scale at top), (b) vertical shear of zonal wind $\left(\mathrm{m} \mathrm{s}^{-1}\right)$, and (c) 500 -hPa vertical $p$ velocity $\left(10^{-2} \mathrm{~Pa} \mathrm{~s}^{-1}\right)$ in years of large TWNP intensity with normal ECP SST in SON. Thick contours denote that the composite mean anomalies are larger than the standard deviation of individual anomalies. Black vectors denote that the length of composite wind anomalies are larger than the magnitude of standard deviation of individual zonal and meridional wind anomalies. Only wind vectors with the magnitude larger than $0.3 \mathrm{~m} \mathrm{~s}^{-1}$ are plotted.

Table 4). The fourth term is small from the seasonal mean flow (Fig. 15g; Table 4). The four terms associated with the intraseasonal flow display small-scale features (Figs. 15b,d,f,h). Based on the area-mean anomalies over the TWNP, the first term is negative and the fourth term is positive (Table 4). These features are similar to those in the years of large TWNP intensity except for an opposite sign.

In the years of large TWNP intensity with normal ECP SST (figure not shown), the first term, third term, and fourth term associated with the seasonal mean flow have a positive contribution, whereas the second term associated with the seasonal mean flow has a negative contribution to the kinetic energy anomalies north of $20^{\circ} \mathrm{N}$. The first term has a dominant positive contribution and the second term has a supplementary contribution to the kinetic energy anomalies south of $20^{\circ} \mathrm{N}$. The first and third terms associated with the intraseasonal flow have a positive contribution, whereas the fourth term associated with the intraseasonal flow has a negative contribution south of $20^{\circ} \mathrm{N}$. The second and third terms associated with the intraseasonal flow have a positive contribution north of $20^{\circ} \mathrm{N}$. In the type of years of normal TWNP intensity with normal ECP SST, both seasonal mean and intraseasonal flows have a negative contribution with a larger value associated with the intraseasonal flow. In the type of years of normal TWNP intensity KE with high and low ECP SST, the seasonal mean and intraseasonal flow contributions are comparable and tend to cancel each other.

\section{Summary and discussion}

The present study documented the factors of interannual variations in the intensity of the SSV over the TWNP in boreal summer and fall separately. Our analysis illustrates the complexity of the relationship of the intensity of the TWNP SSV to equatorial central-eastern Pacific SST and reveals notable differences in the relationship between summer and fall. It is found that the intensity of summer TWNP SSV has a positive correlation with SST in the Niño-3.4 region, whereas the intensity of fall TWNP SSV has a positive correlation with SST in the ECP region. Several different types of relationships are identified in both summer and fall. These are described below.

The SSV in summer can be enhanced in El Niño years and weakened in La Niña years over the TWNP. In El Niño years, positive SST anomalies in the equatorial central-eastern Pacific induce low-level cyclonic wind anomalies, anomalous ascent, and anomalous easterly vertical shear that extend northwestward from the equatorial central Pacific to the TWNP via a Rossby wave-type response. The above background field changes are supplemented by opposite-sign SST anomalies in the tropical southeastern Indian Ocean via a cross-equatorial overturning circulation. Consequently, the background fields are favorable both in the source region and along the propagation path of the synoptic-scale disturbances, leading to enhanced SSV over the TWNP. Opposite changes in the background fields are induced in La Niña years, leading to suppressed SSV over the TWNP.

Our analysis shows that the ECP SST anomalies may or may not lead to obvious changes in the intensity of the TWNP SSV in fall. The ECP SST anomalies induce low-level wind and vertical motion anomalies extending from the ECP to the TWNP via a Rossby wave-type response when there are coexisting opposite-sign SST anomalies in the TWNP and thus modulate the intensity of the SSV over the TWNP. Without the support of opposite-sign SST anomalies in the TWNP, the ECP SST anomaly-induced wind and vertical motion anomalies are limited to the ECP and thus cannot cause notable changes in the intensity of the SSV over the TWNP. Local SST anomalies alone may also play a role in altering the low-level wind and midlevel vertical motion via a Rossby wave-type response and thus modulating the intensity of the SSV over the TWNP. 

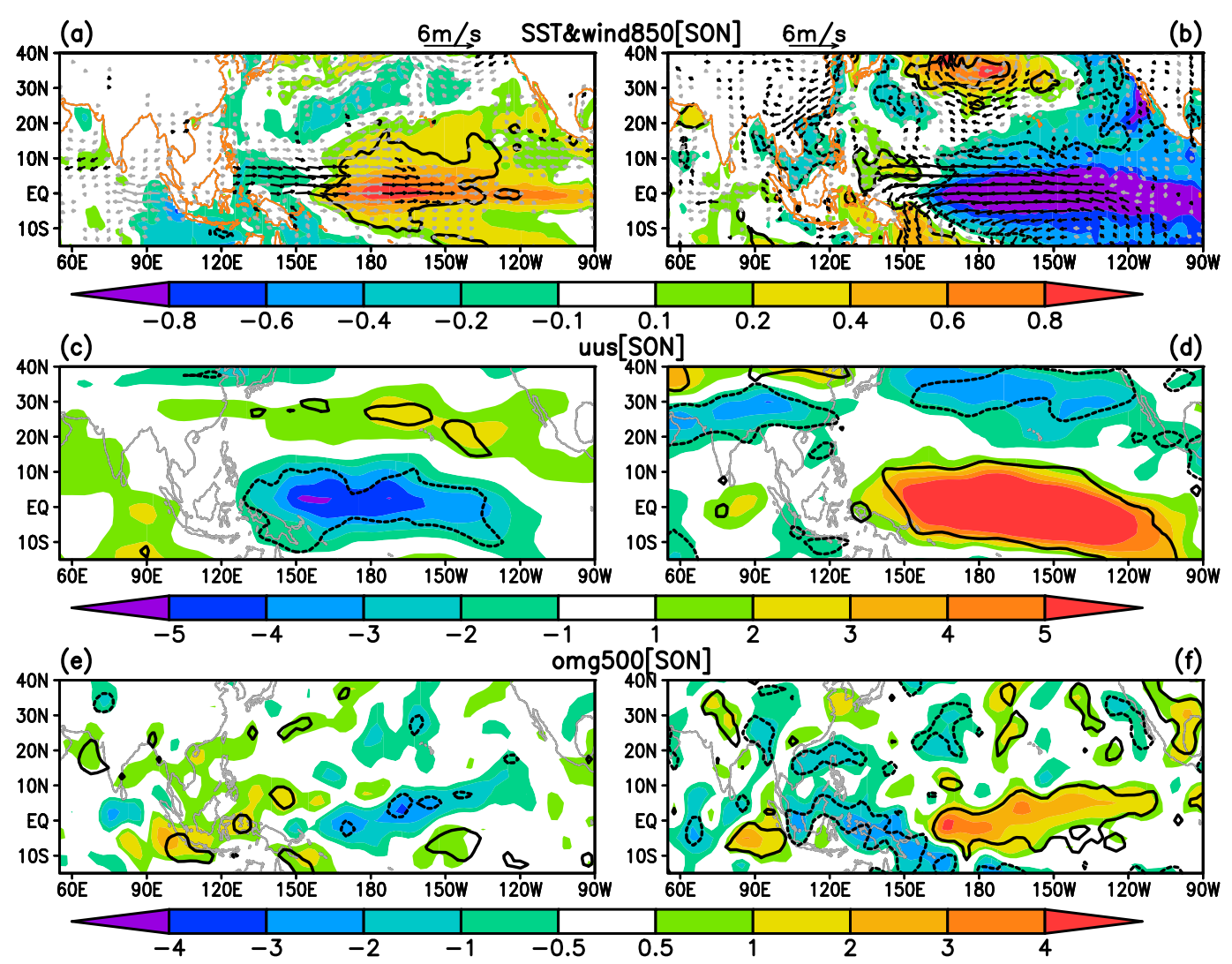

FIG. 13. Composite anomalies of (a),(b) SST (shading; ${ }^{\circ} \mathrm{C}$ ) and 850 -hPa wind anomalies (vectors; $\mathrm{m} \mathrm{s}^{-1}$; $\mathrm{scale}$ at top), (c),(d) vertical shear of zonal wind $\left(\mathrm{m} \mathrm{s}^{-1}\right)$, and (e),(f) 500-hPa vertical $p$ velocity $\left(10^{-2} \mathrm{~Pa} \mathrm{~s}^{-1}\right)$ in years of normal TWNP intensity with (a),(c),(e) high ECP SST and (b),(d),(f) low ECP SST in SON. Thick contours denote that the composite mean anomalies are larger than the standard deviation of individual anomalies. Black vectors denote that the length of composite wind anomalies are larger than the magnitude of standard deviation of individual zonal and meridional wind anomalies. Only wind vectors with the magnitude larger than $0.3 \mathrm{~m} \mathrm{~s}^{-1}$ are plotted.

The analysis of the barotropic energy conversion suggests that the source of energy from both seasonal mean and intraseasonal flows is important for the year-to-year change in the intensity of synoptic-scale disturbances over the TWNP in summer. The major terms of the barotropic energy conversion are related to the meridional shear of zonal wind and zonal wind convergence. Thus, a major mechanism that modulates the seasonal mean intensity of the TWNP SSV in summer is the SST-induced changes in seasonal mean and intraseasonal lower-level winds. In comparison, the contribution of intraseasonal flow is located at higher latitudes than that of seasonal mean flow. In fall, the contribution of intraseasonal flow has a small spatial scale and the contribution of seasonal mean flow appears to be more important for the year-to-year change in the intensity of synoptic-scale disturbances over the TWNP. Thus, a major mechanism that modulates the seasonal mean intensity of the TWNP SSV in fall is the SST-induced changes in seasonal mean lower-level winds.

Our analysis identifies large changes in the intensity of the TWNP SSV in summer without obvious SST anomalies. This indicates that internal atmospheric processes may play an important role in modulating the intensity of the SSV over the TWNP. An issue is what the relative contributions are of the SST forcing and internal atmospheric processes in the year-to-year variations in the intensity of the SSV over the TWNP. Further studies are needed to address this issue.

Our analysis reveals that the intensity of summer and fall TWNP SSV is related to the equatorial SST anomalies in different location: in the equatorial central-eastern Pacific in summer and in the equatorial central Pacific in fall. In fall, the TWNP SSV has a weak relation to the equatorial eastern Pacific SST. The above difference is related to the temporal evolution of ENSO-related background fields. The ENSO-related wind anomalies move eastward from developing to mature phase over the tropical Pacific Ocean (e.g., Wang et al. 2003; Wu et al. 2003; Wu and Song 2018). During El Niño developing summer, cyclonic wind anomalies extend westward to the Indochina Peninsula. During fall, the South China Sea is replaced by an anomalous anticyclone and the cyclonic wind anomalies move to the TWNP. Following the eastward move of cyclonic wind anomalies, the region favorable to the conversion of barotropic energy from mean flow to the synoptic-scale disturbance 

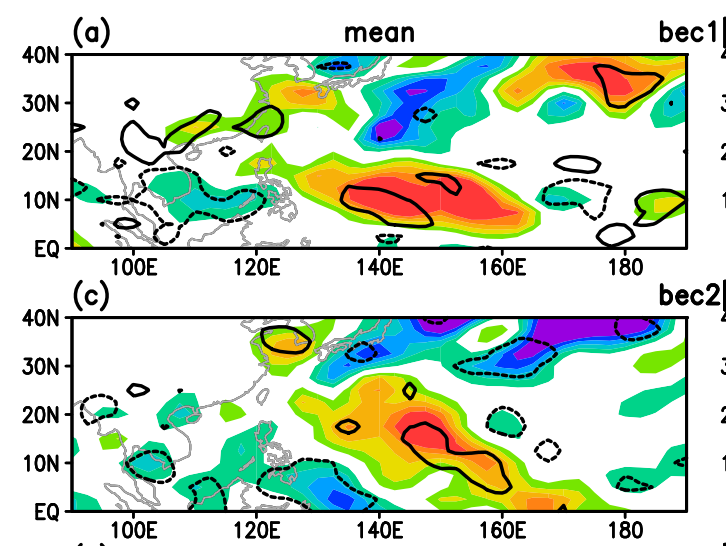

bec2[SON]

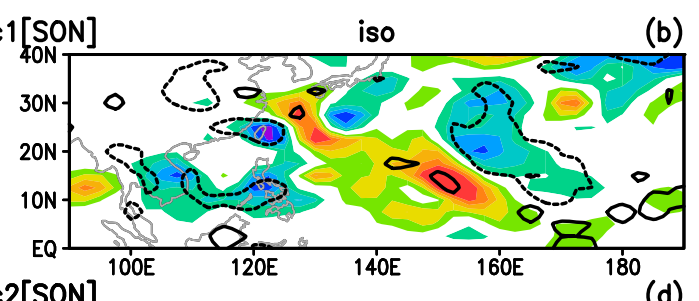

(b)
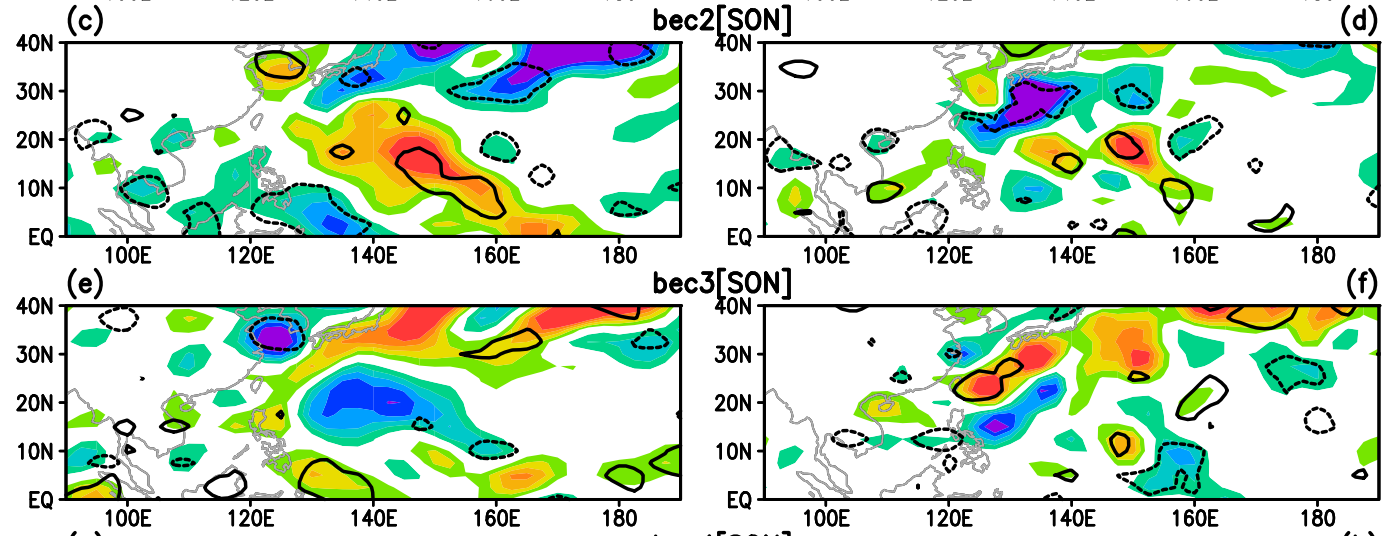

bec3[SON]
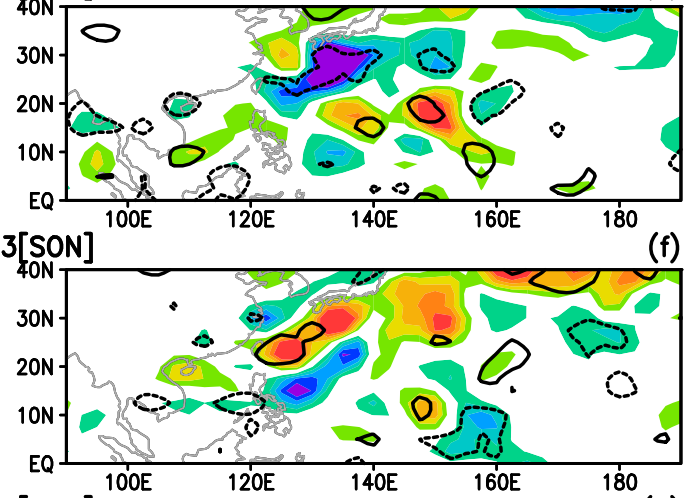

(g)

bec4[SON]

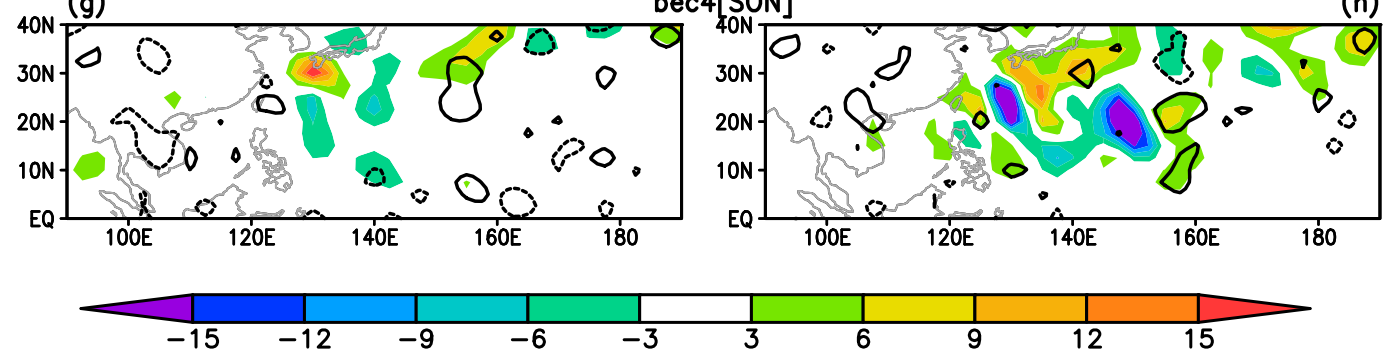

FIG. 14. Composite anomalies $\left(10^{-6} \mathrm{~m}^{2} \mathrm{~s}^{-3}\right)$ of four terms in the equation of barotropic kinetic energy conversion in years of large TWNP intensity with high ECP SST associated with (a),(c),(e),(g) seasonal mean and (b),(d),(f),(h) intraseasonal flows in SON. Thick contours denote that the composite mean anomalies are larger than the standard deviation of individual anomalies. (top to bottom) The terms related to the meridional shear of mean zonal wind, the convergence of mean zonal wind, the convergence of mean meridional wind, and the zonal shear of mean meridional wind, respectively.

moves eastward as well. Accordingly, the area-mean TWNP $\mathrm{KE}$ intensity has a weaker correlation with the equatorial eastern Pacific SST in fall than in summer. Statistically, the weak relation of the TWNP SSV to the equatorial eastern Pacific SST in fall is due to the two different types of cases. In one type of cases, enhanced TWNP SSV is associated with higher SST extending from the equatorial central to eastern Pacific, whereas in the other type of cases, enhanced TWNP SSV is related to lower SST in the equatorial eastern Pacific.

The present analysis focuses on tropical atmospheric circulation changes in relation to changes in the intensity of the TWNP SSV. Examination of composite 200- and 850 -hPa wind anomalies for the second type of years in fall reveals an atmospheric wave train over the North Atlantic and Eurasia with an equivalent barotropic vertical structure (figure not shown). This suggests that the midlatitude atmospheric circulation changes may affect the intensity of the SSV over the TWNP in fall. Issues of worthy of investigation are to what extent and through which processes the midlatitude atmospheric circulation changes modulate the intensity of the TWNP SSV.

The present composite analysis is based on the cases determined based on two indices. It helps to unravel the plausible reasons behind the different types of relationships. However, the number of samples is limited in each type of categories.

TABLE 4. Area-mean composite anomalies $\left(10^{-6} \mathrm{~m}^{2} \mathrm{~s}^{-3}\right)$ of four terms in the equation of barotropic kinetic energy conversion in years of large TWNP intensity with high Niño-3.4 SST and small TWNP KE intensity with low Niño-3.4 SST in SON.

\begin{tabular}{cccccc}
\hline \hline & \multicolumn{2}{c}{ Large KE-positive SST } & & \multicolumn{2}{c}{ Small KE-negative SST } \\
\cline { 2 - 3 } \cline { 6 - 6 } Type & $\begin{array}{c}\text { Mean } \\
\text { flow }\end{array}$ & $\begin{array}{c}\text { Intraseasonal } \\
\text { flow }\end{array}$ & & $\begin{array}{c}\text { Mean } \\
\text { flow }\end{array}$ & $\begin{array}{c}\text { Intraseasonal } \\
\text { flow }\end{array}$ \\
\hline Term 1 & 3.07 & 2.33 & & -3.50 & -3.47 \\
Term 2 & 5.21 & -1.75 & & -3.37 & 0.11 \\
Term 3 & -3.43 & 0.83 & & 4.00 & 1.32 \\
Term 4 & -1.03 & 1.98 & & 0.39 & 2.40 \\
\hline
\end{tabular}



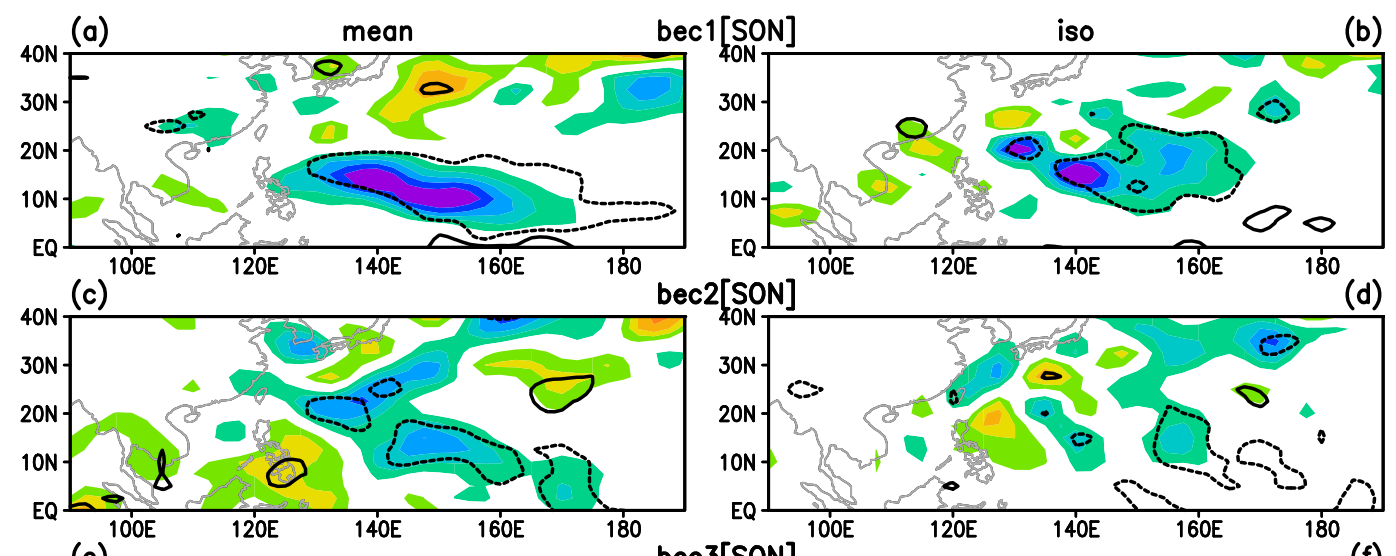

(d)
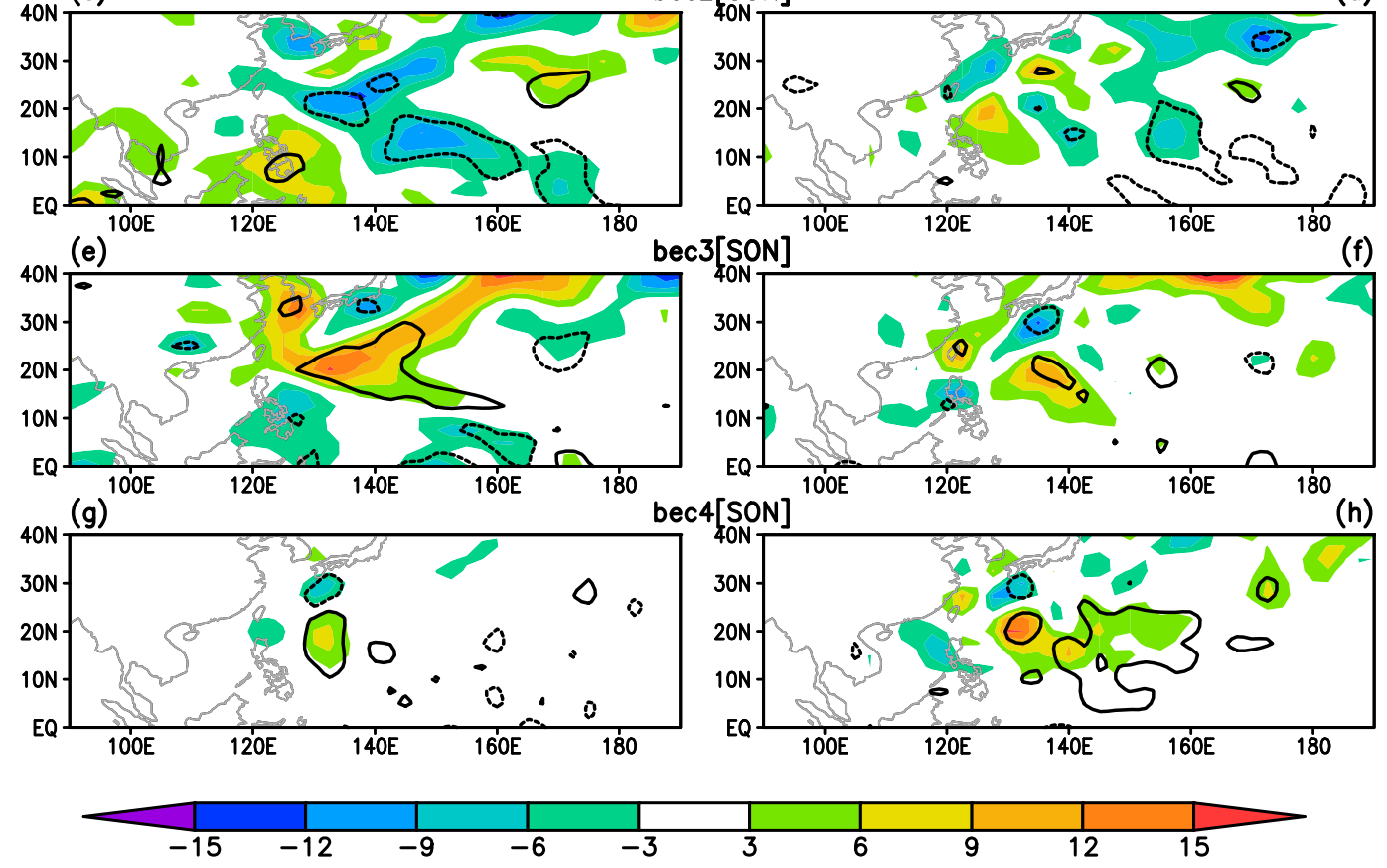

FIG. 15. As in Fig. 14, but in years of small TWNP intensity with low ECP SST.

This raises an issue about the robustness of the obtained results. Further analysis is needed to confirm the conclusions obtained in the present study.

Acknowledgments. The comments of three anonymous reviewers have helped the improvement of this paper. This study is supported by National Natural Science Foundation of China grants $(41775080,41721004$, and 41530425). The NCEP-DOE Reanalysis 2 data were obtained from ftp://ftp.cdc.noaa.gov/. The NOAA OI version 2 SST data were obtained from http:// www.esrl.noaa.gov/psd/.

\section{REFERENCES}

Cao, X., and R. Wu, 2018: Comparison of different time scale contributions to tropical cyclone genesis over the western North Pacific in 2015 and 2016. J. Meteor. Soc. Japan, 96, 317336, https://doi.org/10.2151/jmsj.2018-038.

- - P. Huang, G.-H. Chen, and W. Chen, 2012: Modulation of western North Pacific tropical cyclone genesis by intraseasonal oscillation of the ITCZ: A statistical analysis. Adv. Atmos. Sci., 29, 744-754, https://doi.org/10.1007/s00376-012-1121-0.

_- R. Wu, and M.-Y. Bi, 2018: Contributions of different time scale variations to tropical cyclogenesis over the western North Pacific. J. Climate, 31, 3137-3153, https://doi.org/ 10.1175/JCLI-D-17-0519.1.
Capotondi, A., and Coauthors, 2015: Understanding ENSO diversity. Bull. Amer. Meteor. Soc., 96, 921-938, https://doi.org/ 10.1175/BAMS-D-13-00117.1.

Chen, G., and R.-H. Huang, 2009: Interannual variations in mixed Rossby-gravity waves and their impacts on tropical cyclogenesis over the western North Pacific. J. Climate, 22, 535-549, https://doi.org/10.1175/2008JCLI2221.1.

— waves to tropical cyclogenesis over the western North Pacific. Mon. Wea. Rev., 142, 79-93, https://doi.org/10.1175/MWR-D13-00207.1.

Chen, T.-C., and S.-P. Weng, 1998: Interannual variation of the summer synoptic-scale disturbance activity in the western tropical Pacific. Mon. Wea. Rev., 126, 1725-1733, https://doi.org/ 10.1175/1520-0493(1998)126<1725:IVOTSS > 2.0.CO;2.

— J.-D. Tsay, M.-C. Yen, and J. Matsumoto, 2012: Interannual variation of the late fall rainfall in central Vietnam. J. Climate, 25, 392-413, https://doi.org/10.1175/JCLI-D-11-00068.1.

Fu, B., T. Li, M. S. Peng, and F.-Z. Weng, 2007: Analysis of tropical cyclogenesis in the western North Pacific for 2000 and 2001. Wea. Forecasting, 22, 763-780, https://doi.org/ 10.1175/WAF1013.1.

Fukutomi, Y., C. Kodama, Y. Yamada, A. T. Noda, and M. Satoh, 2016: Tropical synoptic-scale wave disturbances over the western Pacific simulated by a global cloud-system resolving model. Theor. Appl. Climatol., 124, 737-755, https://doi.org/ 10.1007/s00704-015-1456-4. 
He, Z., and R. Wu, 2014: Indo-Pacific remote forcing in summer rainfall variability over the South China Sea. Climate Dyn., 42, 2323-2337, https://doi.org/10.1007/s00382-014-2123-7.

Holland, G. J., 1995: Scale interaction in the western Pacific monsoon. Meteor. Atmos. Phys., 56, 57-79, https://doi.org/ 10.1007/BF01022521.

Hsu, P.-C., C.-H. Tsou, H.-H. Hsu, and J.-H. Chen, 2009: Eddy energy along the tropical storm track in association with ENSO. J. Meteor. Soc. Japan, 87, 687-704, https://doi.org/ 10.2151/jmsj.87.687.

— , T. Li, and C.-H. Tsou, 2011: Interactions between boreal summer intraseasonal oscillations and synoptic-scale disturbances over the western North Pacific. Part I: Energetics diagnosis. J. Climate, 24, 927-941, https://doi.org/10.1175/2010JCLI3833.1.

Hurley, J. V., and W. R. Boos, 2015: A global climatology of monsoon low-pressure systems. Quart. J. Roy. Meteor. Soc., 141, 1049-1064, https://doi.org/10.1002/qj.2447.

Kanamitsu, M., W. Ebisuzaki, J. Woollen, S.-K. Yang, J. J. Hnilo, M. Fiorino, and G. L. Potter, 2002: NCEP-DOE AMIP-II Reanalysis (R-2). Bull. Amer. Meteor. Soc., 83, 1631-1644, https://doi.org/10.1175/BAMS-83-11-1631.

Kirtman, B., 2019: Special issue: ENSO diversity. Climate Dyn., 52, 7133, https://doi.org/10.1007/s00382-019-04723-2.

Lau, K.-H., and N.-C. Lau, 1990: Observed structure and propagation characteristics of tropical summertime synoptic-scale disturbances. Mon. Wea. Rev., 118, 1888-1913, https://doi.org/ 10.1175/1520-0493(1990)118<1888:OSAPCO > 2.0.CO;2.

— , and — 1992: The energetics and propagation dynamics of tropical summertime synoptic-scale disturbances. Mon. Wea. Rev., 120, 2523-2539, https://doi.org/10.1175/1520-0493(1992) $120<2523$ :TEAPDO $>2.0 . \mathrm{CO} ; 2$.

Li, R. C.-Y., and W. Zhou, 2012: Changes in western Pacific tropical cyclones associated with the El Niño-Southern Oscillation cycle. J. Climate, 25, 5864-5878, https://doi.org/10.1175/JCLID-11-00430.1.

— - — , and T. Li, 2014: Influences of the Pacific-Japan teleconnection pattern on synoptic-scale variability in the western North Pacific. J. Climate, 27, 140-154, https://doi.org/10.1175/ JCLI-D-13-00183.1.

Li, T., 2006: Origins of the summertime synoptic-scale wave train in the western North Pacific. J. Atmos. Sci., 63, 1093-1102, https://doi.org/10.1175/JAS3676.1.

Lindzen, R. S., and N. Nigam, 1987: On the role of sea surface temperature gradients in forcing low-level winds and convergence in the tropics. J. Atmos. Sci., 44, 2418-2436, https://doi.org/ 10.1175/1520-0469(1987)044<2418:OTROSS $>2.0 . C O ; 2$.

Maloney, E. D., and D. L. Hartmann, 2001: The Madden-Julian oscillation, barotropic dynamics, and North Pacific tropical cyclone formation. Part I: Observations. J. Atmos. Sci., 58, 2545-2558, https://doi.org/10.1175/1520-0469(2001)058<2545: TMJOBD $>2.0 . \mathrm{CO} ; 2$.

— , and M. J. Dickinson, 2003: The intraseasonal oscillation and the energetics of summertime tropical western North Pacific synoptic-scale disturbances. J. Atmos. Sci., 60, 2153-2168, https:// doi.org/10.1175/1520-0469(2003)060<2153:TIOATE >2.0.CO;2.

Molinari, J., and D. Vollaro, 2013: What percentage of western North Pacific tropical cyclones form within the monsoon trough? Mon. Wea. Rev., 141, 499-505, https://doi.org/10.1175/MWRD-12-00165.1.

Reynolds, R. W., N. A. Rayner, T. M. Smith, D. C. Stokes, and W. Wang, 2002: An improved in situ and satellite SST analysis for climate. J. Climate, 15, 1609-1625, https://doi.org/10.1175/ 1520-0442(2002)015<1609:AIISAS > 2.0.CO;2.
Ritchie, E. A., and G. J. Holland, 1997: Scale interactions during the formation of Typhoon Irving. Mon. Wea. Rev., 125, 1377-1396, https://doi.org/10.1175/1520-0493(1997)125<1377: SIDTFO $>2.0 . \mathrm{CO} ; 2$.

Sobel, A. H., and C. S. Bretherton, 1999: Development of synopticscale disturbances over the summertime tropical northwest Pacific. J. Atmos. Sci., 56, 3106-3127, https://doi.org/10.1175/ 1520-0469(1999)056<3106:DOSSDO >2.0.CO;2.

—, and E. D. Maloney, 2000: Effects of ENSO and the MJO on the western North Pacific tropical cyclones. Geophys. Res. Lett., 27, 1739-1742, https://doi.org/10.1029/1999GL011043.

Straub, K. H., and G. N. Kiladis, 2003: Interactions between the boreal summer intraseasonal oscillation and higher-frequency tropical wave activity. Mon. Wea. Rev., 131, 945-960, https:// doi.org/10.1175/1520-0493(2003)131<0945:IBTBSI>2.0.CO;2.

Tsou, C.-H., H.-H. Hsu, and P.-C. Hsu, 2014: The role of multiscale interaction in synoptic-scale eddy kinetic energy over the western North Pacific in autumn. J. Climate, 27, 3750-3766, https://doi.org/10.1175/JCLI-D-13-00380.1.

Wang, B., R. Wu, and X. Fu, 2000: Pacific-East Asian teleconnection: How does ENSO affect East Asian climate? J. Climate, 13, 1517-1536, https://doi.org/10.1175/1520-0442(2000)013<1517: PEATHD $>2.0 . \mathrm{CO} ; 2$.

,-- , and T. Li, 2003: Atmosphere-warm ocean interaction and its impacts on the Asian-Australian monsoon variation. J. Climate, 16, 1195-1211, https://doi.org/10.1175/1520-0442(2003) 16<1195:AOIAII $>2.0$. CO;2.

Wang, Y.-Q., R. Wu, and Y. Jiao, 2020: Upscale feedback of highfrequency winds on seasonal SST change over the tropical western North Pacific during boreal summer. Climate Dyn., 55, 2439-2451, https://doi.org/10.1007/s00382-020-05391-3.

Wu, L., Z.-P. Wen, R.-H. Huang, and R. Wu, 2012: Possible linkage between the monsoon trough variability and the tropical cyclone activity over the western North Pacific. Mon. Wea. Rev., 140, 140-150, https://doi.org/10.1175/MWR-D-11-00078.1.

, T. Li, and R. Huang, 2014: ENSO-phase dependent TD and MRG wave activity in the western North Pacific. Climate Dyn., 42, 1217-1227, https://doi.org/10.1007/s00382013-1754-4.

_ _ _ a and R. Wu, 2015a: Influence of the monsoon trough on westward-propagating tropical waves over the western North Pacific. Part I: Observations. J. Climate, 28, 7108-7127, https:// doi.org/10.1175/JCLI-D-14-00806.1.

_ Z. Wen, and R. Wu, 2015b: Influence of the monsoon trough on westward-propagating tropical waves over the western North Pacific. Part II: Energetics and numerical experiments. J. Climate, 28, 9332-9349, https://doi.org/10.1175/JCLI-D-1400807.1.

—, H. Zhang, J.-M. Chen, and T. Feng, 2018: Impact of two types of El Niño on tropical cyclones over the western North Pacific: Sensitivity to location and intensity of Pacific warming. J. Climate, 31, 1725-1742, https://doi.org/10.1175/JCLI-D-170298.1.

Wu, P., Y. Fukutomi, and J. Matsumoto, 2011: An observational study of the extremely heavy rain event in northern Vietnam during 30 October-1 November 2008. J. Meteor. Soc. Japan, 89A, 331-344, https://doi.org/10.2151/jmsj.2011-A23.

Wu, R., and B. Wang, 2000: Interannual variability of summer monsoon onset over the western North Pacific and the underlying processes. J. Climate, 13, 2483-2501, https://doi.org/ 10.1175/1520-0442(2000)013<2483:IVOSMO > 2.0.CO;2.

_ , and L. Song, 2018: Spatiotemporal change of intraseasonal oscillation intensity over the tropical Indo-Pacific Ocean 
associated with El Niño and La Niña events. Climate Dyn., $\mathbf{5 0}$, 1221-1242, https://doi.org/10.1007/s00382-017-3675-0.

_ Z.Z.Z. Hu, and B. P. Kirtman, 2003: Evolution of ENSO-related rainfall anomalies in East Asia. J. Climate, 16, 3742-3758, https:// doi.org/10.1175/1520-0442(2003)016<3742:EOERAI >2.0.CO;2.

_, S. Yang, Z.-P. Wen, G. Huang, and K. Hu, 2012: Interdecadal change in the relationship of southern China summer rainfall with tropical Indo-Pacific SST. Theor. Appl. Climatol., 108, 119-133, https://doi.org/10.1007/s00704-011-0519-4.

— , G. Huang, Z. Du, and K. Hu, 2014: Cross-season relation of the South China Sea precipitation variability between winter and summer. Climate Dyn., 43, 193-207, https://doi.org/10.1007/ s00382-013-1820-y.

_ , Y.-Y. Yang, and X. Cao, 2019: Respective and combined impacts of regional SST anomalies on tropical cyclogenesis in different sectors of the western North Pacific. J. Geophys. Res. Atmos., 124, 8917-8934, https://doi.org/10.1029/2019JD030736.

_- Y. Wang, and Y. Jiao, 2020a: High frequency wind-related seasonal mean latent heat flux changes. Climate Dyn., 55, 3269-3287, https://doi.org/10.1007/s00382-020-05445-6..

_, Y. Jiao, Y. Wang, and X.-J. Jia, 2020b: High-frequency windrelated seasonal mean latent heat flux changes over the tropical Indo-western Pacific in El Niño and La Niña years. J. Geophys. Res. Atmos., 125, e2020JD032954, https://doi.org/ 10.1029/2020JD032954..
Xie, S.-P., K.-M. Hu, J. Hafner, H. Tokinaga, Y. Du, G. Huang, and T. Sampe, 2009: Indian Ocean capacitor effect on Indo-western Pacific climate during the summer following El Niño. J. Climate, 22, 730-747, https://doi.org/10.1175/2008JCLI2544.1.

Yang, Y.-Y., R. Wu, and C.-H. Wang, 2020: Individual and combined impacts of tropical Indo-Pacific SST anomalies on interannual variation of the Indochina peninsular precipitation. J. Climate, 33, 1069-1088, https://doi.org/10.1175/JCLI-D-190262.1.

Zhao, H., X. Jiang, and L. Wu, 2015a: Modulation of northwest Pacific tropical cyclone genesis by the intraseasonal variability. J. Meteor. Soc. Japan, 93, 81-97, https://doi.org/10.2151/ jmsj.2015-006.

_, R. Yoshida, and G. B. Raga, 2015b: Impact of the MaddenJulian Oscillation on western North Pacific tropical cyclogenesis associated with large-scale patterns. J. Appl. Meteor. Climatol., 54, 1413-1429, https://doi.org/10.1175/JAMC-D-14-0254.1.

_ waves over the western North Pacific in multimodel simulations. J. Climate, 29, 4487-4508, https://doi.org/10.1175/JCLID-15-0696.1.

Zhou, X.-Y., R.-Y. Lu, G.-H. Chen, and L. Wu, 2018: Interannual variations in synoptic-scale disturbances over the western North Pacific. Adv. Atmos. Sci., 35, 507-517, https://doi.org/ 10.1007/s00376-017-7143-x. 